\title{
Modulation of Rhythmic Activity in Mammalian Spinal Networks Is Dependent on Excitability State
}

\author{
- Simon A. Sharples, ${ }^{1}$ and ${ }^{-P}$ Patrick J. Whelan ${ }^{1,2}$
}

DOI:http://dx.doi.org/10.1523/ENEURO.0368-16.2017

${ }^{1}$ Hotchkiss Brain Institute, University of Calgary, Calgary, Alberta T2N 4N1, Canada, ${ }^{2}$ Department of Comparative Biology and Experimental Medicine, University of Calgary, Calgary, AB T2N 4N1, Canada

\section{Visual Abstract}
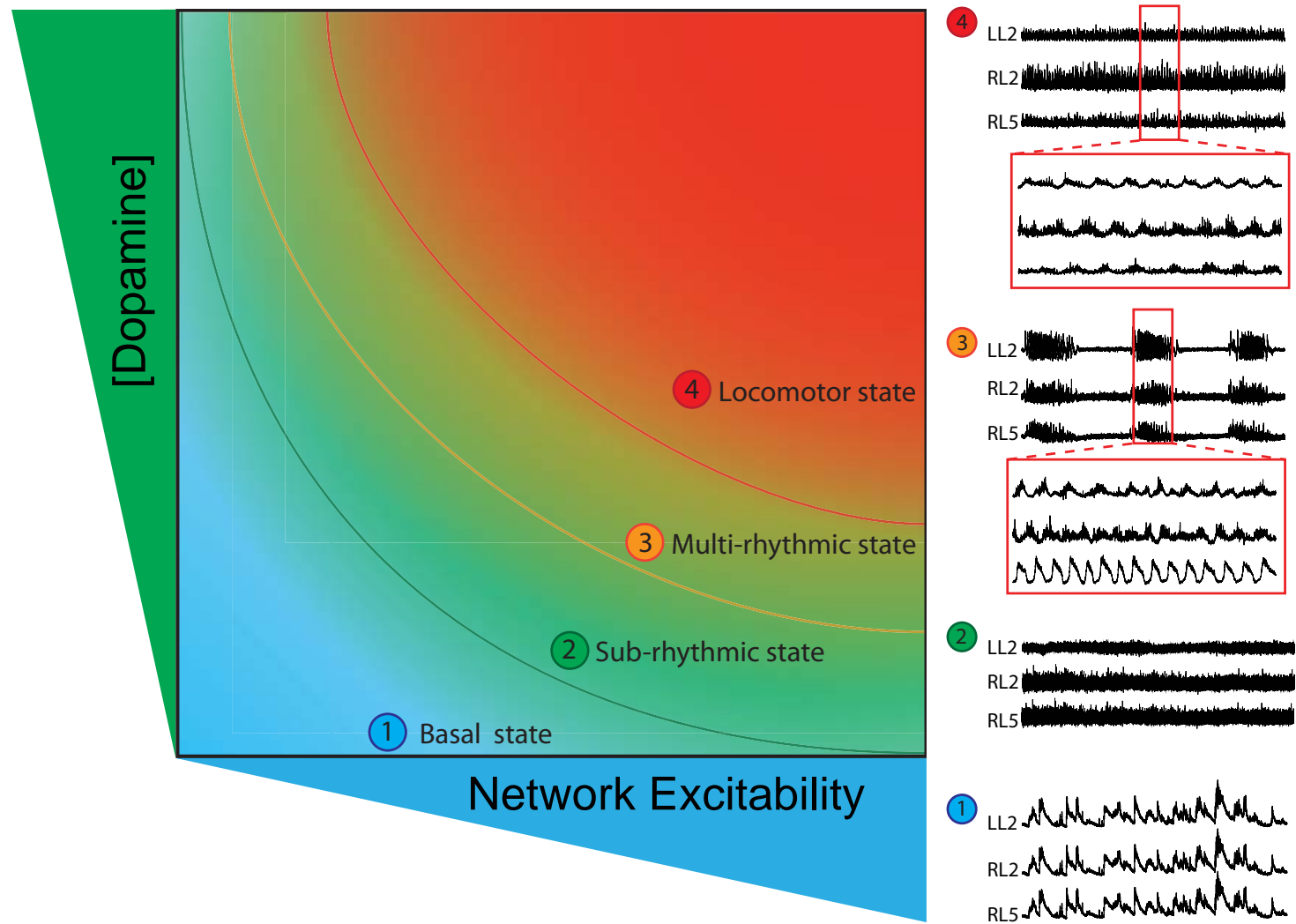

\section{Significance Statement}

We show that, as in the invertebrate systems, the action of monoamine modulators on rhythmic motor networks of the mammalian spinal cord is state dependent. Our work shows that neuromodulation in the spinal cord is fundamentally linked to the excitability state of the network. These findings have broad significance on mammalian network function since variations in network excitation can account for (1) diversity of neuromodulator function, which (2) is an additional factor that must be considered when circuit elements are removed from a network to infer network function and (3) can account for the variability often found between experimental preparations. 
Neuromodulators play an important role in activating rhythmically active motor networks; however, what remains unclear are the network interactions whereby neuromodulators recruit spinal motor networks to produce rhythmic activity. Evidence from invertebrate systems has demonstrated that the effect of neuromodulators depends on the pre-existing state of the network. We explored how network excitation state affects the ability of dopamine to evoke rhythmic locomotor activity in the neonatal mouse isolated spinal cord. We found that dopamine can evoke unique patterns of motor activity that are dependent on the excitability state of motor networks. Different patterns of motor activity ranging from tonic, nonrhythmic activity to multirhythmic, nonlocomotor activity to locomotor activity were produced by altering global motor network excitability through manipulations of the extracellular potassium and bath NMDA concentration. A similar effect was observed when network excitation was manipulated during an unstable multirhythm evoked by a low concentration (15 $\mu \mathrm{M})$ of $5-\mathrm{HT}$, suggesting that our results are not neuromodulator specific. Our data show in vertebrate systems that modulation is a two-way street and that modulatory actions are largely influenced by the network state. The level of network excitation can account for variability between preparations and is an additional factor to be considered when circuit elements are removed from the network.

Key words: CPG; locomotion; network; spinal cord

\section{Introduction}

Rhythmic motor behaviors mediate a number of functions essential to survival, including breathing (Smith et al., 1991; Baghdadwala et al., 2016), feeding (Blitz and Nusbaum, 2012; Stadele et al., 2015), and locomotion (Gordon and Whelan, 2006; Grillner et al., 2008; Sillar et al., 2014; Kiehn, 2016). In vertebrates, neuronal networks within the spinal cord control rhythmic movements of the limbs and axial musculature to produce various forms of locomotion (Hultborn and Nielsen, 2007; Roberts et al., 2012; Kimura et al., 2013; Kiehn, 2016). While these networks have the capacity to function in isolation, normally they are modulated by inputs from the brain (Miles and Sillar, 2011; Koblinger et al., 2014; Sharples et al., 2015) and brainstem (van den Pol, 1999; Hentall et al., 2003; Jordan et al., 2008; Bouvier et al., 2015), and by sensory feedback from the limbs (Whelan et al., 1995). Collectively, these inputs endow these networks with the flexibility to produce diverse patterns of rhythmicity to suit the task at hand (Jordan et al., 2008; Sillar et al., 2014; Marder et al., 2015). Although evoked rhythms in the spinal cord have been characterized by others including our group, and diversity reported, we are not aware of this

Received December 12, 2016; accepted January 12, 2017; First published January 19, 2017

The authors declare no competing financial interests.

Authors contributions: P.J.W. designed research; S.A.S. performed research; S.A.S. analyzed data; S.A.S. and P.J.W. wrote the paper.

Funding for S.A.S. was provided by the Natural Sciences and Engineering Research Council of Canada (NSERC-PGS-D), Alberta Innovates Health Solutions, and a Dr. T. Chen Fong Doctoral Scholarship from the Hotchkiss Brain Institute. This research is supported by grants provided by the Canadian Institute of Health Research (P.J.W.) and a NSERC Discovery grant (P.J.W.).

Acknowledgments: We thank Jillian Ejdrygiewicz and Claude Viellet for their technical assistance during the completion of this work. We also thank Dr. Tuan Bui for helpful comments on the manuscript, Dr. Celine Jean-Xavier for helpful discussions, and Kyle Mayr for assisting with Figure 8.

Correspondence should be addressed to Patrick J. Whelan, HMRB 168, 3310 Hospital Drive NW, Calgary, Alberta T2N 4N1, Canada. E-mail: whelan@ucalgary.ca.

DOI:http://dx.doi.org/10.1523/ENEURO.0368-16.2017

Copyright (C) 2017 Sharples and Whelan

This is an open-access article distributed under the terms of the Creative Commons Attribution 4.0 International, which permits unrestricted use, distribution and reproduction in any medium provided that the original work is properly attributed. diversity being explained in terms of a modulatoryexcitation state space (Cowley and Schmidt, 1997; Pearson et al., 2003; Madriaga et al., 2004; Barrière et al., 2005; Christie and Whelan, 2005; Gordon and Whelan, 2006; Puhl and Mesce, 2008; Humphreys and Whelan, 2012; Gozal et al., 2014; Heckman and Johnson, 2014).

The importance of excitation state is evident from examples provided in the small circuits of the stomatogastric nervous system whereby different motor patterns can be modeled as a function of balanced synaptic weights as well as intrinsic properties (Gutierrez et al., 2013; Gutierrez and Marder, 2014). The range of motor patterns generated as a function of varying circuit properties has been termed the circuit state or parameter space. Based on this, it has been proposed that the modulation of circuit output is state dependent and that the influence of a neuromodulator is linked to the relative position of the circuit within its parameter space. Several lines of evidence demonstrates that specific motor patterns can also be achieved through multiple or degenerate mechanisms (Prinz et al., 2004; Gutierrez et al., 2013; Marder et al., 2014).

We show that, as in the invertebrate systems (Bargmann, 2012; Marder et al., 2014), the action of monoamine modulators on rhythmic motor networks of the mammalian spinal cord is state dependent. We explore how network excitation state influences the modulatory effect of dopamine on rhythmically active motor networks in the isolated spinal cord of neonatal mice. This model is advantageous since elements of the circuit have been genetically defined, and the motor output has been well characterized by several laboratories and is starting to be mathematically modeled. Broadly speaking, our data suggest that it is important to consider modulation as a two-way street; modulatory actions are largely influenced by the network state. Our results have functional implications in pathological instances such as in multiple sclerosis, spinal cord injury, and stroke, where spinal cord excitability and stepping performance are compromised. Furthermore, the irregular rhythmic movements we report here may be manifest in neonatal rodents, while spinal networks are maturing and descending projections are developing. At this time, the neonate must still make 

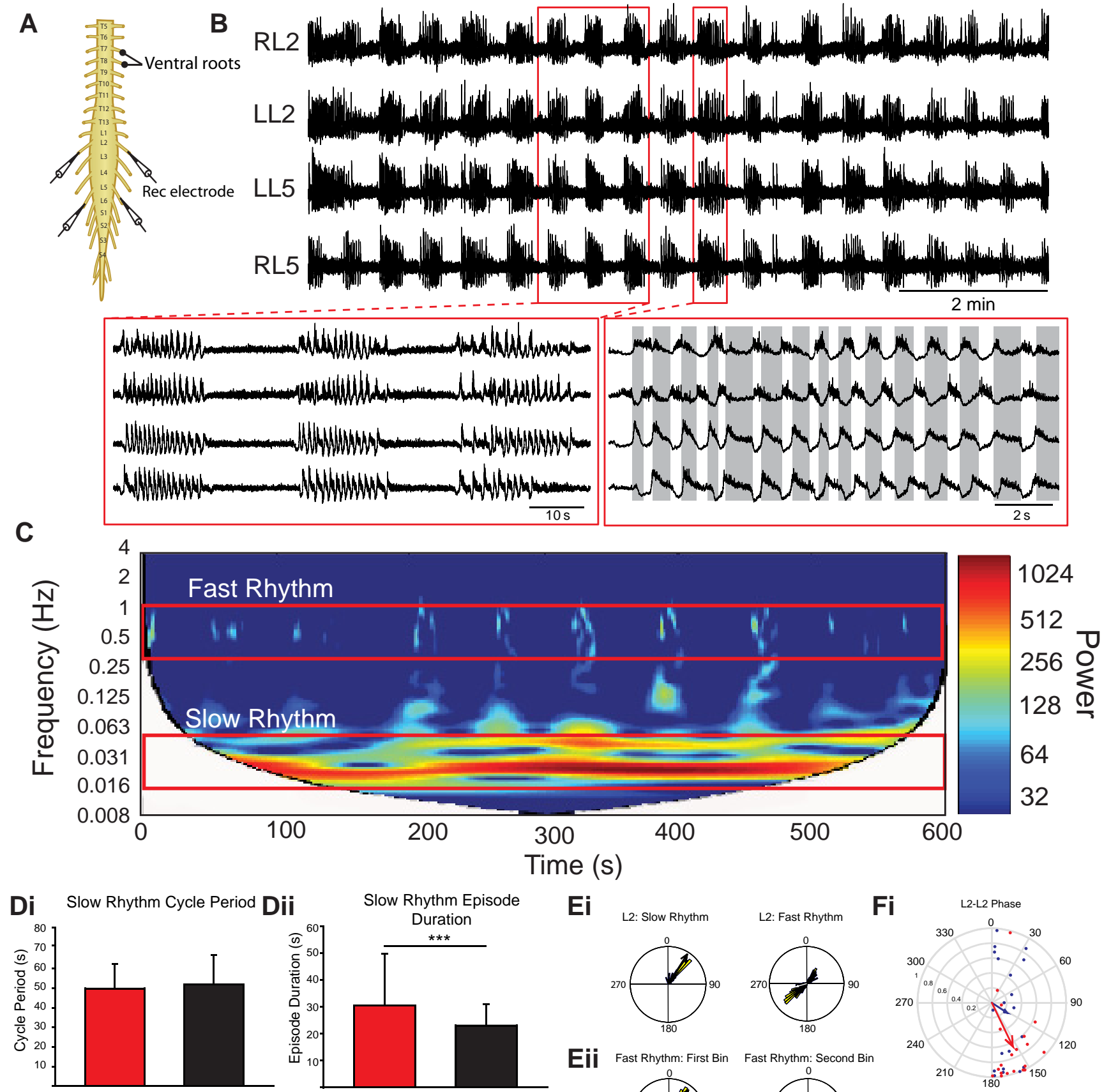

Ei

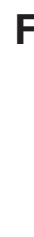

Eii
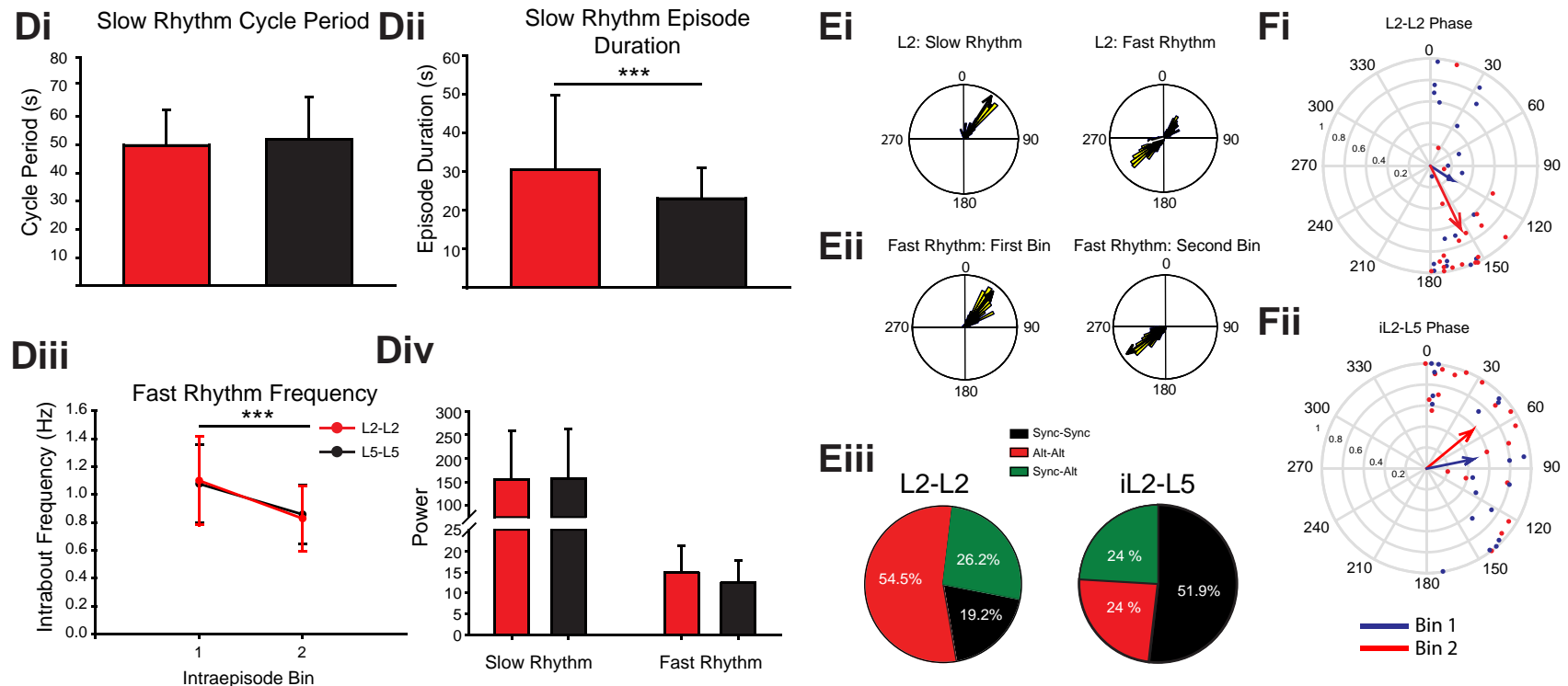

Figure 1. Dopamine evokes multirhythmic patterns of motor activity. $\boldsymbol{A}$, Neurograms recorded from the left and right ventral roots of the L2 and L5 isolated thoracolumbar spinal cord. B. Dopamine evokes a multirhythmic pattern of motor activity that is composed of two rhythms: a slow, synchronous rhythm with a superimposed fast rhythm. $\boldsymbol{C}$, These fast and slow rhythms (red boxes) are apparent when the frequency power is represented over time as a spectrogram with frequency on the left $y$-axis, time on the $x$-axis, 
continued

and warmer colors representing higher frequency power. Di, Dii, Div, The slow rhythm features including cycle period (Di), episode duration (Dii), and power (Div) did not differ between L2 (red bars) and L5 (black bars) segments. Diii, Div, The frequency of the fast rhythm occurring within bouts (Diii) decreases over the course of the bout (Div) with no difference in power between L2 and L5 (Div). Data are displayed as the mean \pm SD. Ei, Example phase plots from a single bout of rhythmic activity recorded from the L2 segment illustrate that the bouts are synchronous, with the fast superimposed rhythm exhibiting a biphasic phase distribution. Eii, Separating the fast rhythm into two bins illustrates that the fast bursts start off synchronous and end alternating. Eiii, The pie charts represent the distribution of the possible patterns over the course of a bout recorded between the left and right L2 and ipsilateral L2-L5 ventral roots. Fi, Reflects the mean phase of all bouts. Fii, The predominantly synchronous bursting pattern in ipsilateral ventral root pairs is represented in the mean phase plot. The phases in circular plots are reported in degrees with the length of arrows representing mean vector length $(r)$ and angle.

movements to move toward the mother. These movements tend to be erratic compared with the full-fledged stepping that occurs around postnatal day 9 (P9) to P10 when complete weight support is realized. Our data also function to provide a reference that investigators can use to interpret variability in rhythmic patterns observed using isolated spinal cord preparations. A portion of these results has been published in abstract form (Sharples and Whelan, 2015).

\section{Materials and Methods}

\section{Ethical approval and animals}

Experiments were performed on male and female neonatal C57BL/6 mice that were 0-4 days old (P0-P3; $N=$ 82). All procedures used were approved by the University of Calgary Health Sciences Animal Care Committee.

\section{Tissue preparation}

Animals were anesthetized by cooling, decapitated, and eviscerated to expose the vertebral column. The remaining tissue was placed ventral side up in a dissection chamber filled with room temperature carbogenated $\left(95 \% \mathrm{O}_{2}, 5 \% \mathrm{CO}_{2}\right)$ artificial CSF (aCSF; in mM: $128 \mathrm{NaCl}$, $4 \mathrm{KCl}, 1.5 \mathrm{CaCl}_{2}, 1 \mathrm{MgSO}_{4}, 0.5 \mathrm{Na}_{2} \mathrm{HPO}_{4}, 21 \mathrm{NaHCO}_{3}$, and $30 \mathrm{D}$-glucose), and spinal cords were exposed via a ventral laminectomy and the dorsal and ventral roots cut. The spinal cord was removed, transferred to a recording chamber, ventral side up, with recirculating carbogenated aCSF at a flow rate of $20 \mathrm{ml} / \mathrm{min}$ and gradually heated from room temperature to $27^{\circ} \mathrm{C}$. This temperature has been used historically by our group and can control for temperature variability when experiments are conducted at room temperature. The spinal cord was allowed another 45-60 min to stabilize in the recording chamber.

\section{Electrophysiological recordings}

Neurograms obtained from ventral roots of the lumbar 2 (L2) segments and the L5 were amplified (1000 times; EX-4, Dagan), bandpass filtered $(0.1-1 \mathrm{kHz})$, digitized (Digidata 1440, Molecular Devices), acquired (2.5 kHz) using Clampex software (Molecular Devices), and saved for off-line analysis. Recorded motor activity was analyzed using custom-written MATLAB scripts, Spike2 (Cambridge Electronics) and Spinal Core (a gift from Professor A. Lev-Tov, Hebrew University of Jerusalem, Jerusalem, Israel; Mor and Lev-Tov, 2007).

\section{Pharmacology}

Patterns of rhythmic motor activity were evoked by bath application of dopamine hydrochloride (Sigma-Aldrich) or serotonin [5-hydroxytryptamine (5-HT)] hydrochloride (Sigma-Aldrich). Spinal motor network excitability was manipulated pharmacologically by altering the concentration of $\mathrm{KCl}(\mathrm{VWR})$ in the bath, applying concentrations of NMDA (2-6 $\mu \mathrm{M}$; Sigma-Aldrich) that were subthreshold to those that are capable of evoking locomotor patterns of activity in our hands (10-12 $\mu \mathrm{m})$ and concentrations of $\mathrm{MgSO}_{4}$ (1.0-2.5 mM; VWR) to reduce but not suppress all network activity. The NMDA receptor antagonist aminophosphonovalerate (APV) was also bath applied at concentrations capable of reducing but not suppressing spontaneous activity ( $5 \mu \mathrm{m}$; Tocris Bioscience).

\section{Data analysis}

Patterns of rhythmic motor activity were analyzed by performing a Morlet cross-wavelet analysis on ventral root recordings made from left and right L2 and L5 spinal segments and ipsilateral L2-L5 pairs (Mor and Lev-Tov, 2007). Autowavelet spectral analysis was conducted on single ventral root recordings for dopamine doseresponse experiments. Spectrograms are displayed with a white V-shaped cone of influence. Frequency power spectrograms were constructed and data were analyzed by selecting regions of interest within the cone of influence. The spectrograms illustrate two distinct rhythms evoked by dopamine at high concentrations, a slow rhythm of $0.01-0.04 \mathrm{~Hz}$, and a fast rhythm at $0.8-1.2 \mathrm{~Hz}$ (Fig. 1B). Regions of interest were selected within these frequency ranges and analyzed over the time course of each experiment. Parameters measured within each region of interest include frequency and power. Circular statistics were also examined to explore aspects of the pattern of bursting between neurograms recorded from root pairs (i.e., alternating, $180^{\circ}$; or synchronous, $0^{\circ} / 360^{\circ}$ ) and include the phase relationship (vector angle) between bursts in the left and right or L2-L5 roots and phase vector length $(r)$. Data analyzed within regions of interest over the course of each experiment were segmented into $30 \mathrm{~s}$ bins and further averaged over $5 \mathrm{~min}$ intervals for statistical analysis. All analyses conducted on rhythmic motor activity were conducted using the data analysis tools available in Spinal Core (Mor and Lev-Tov, 2007). 

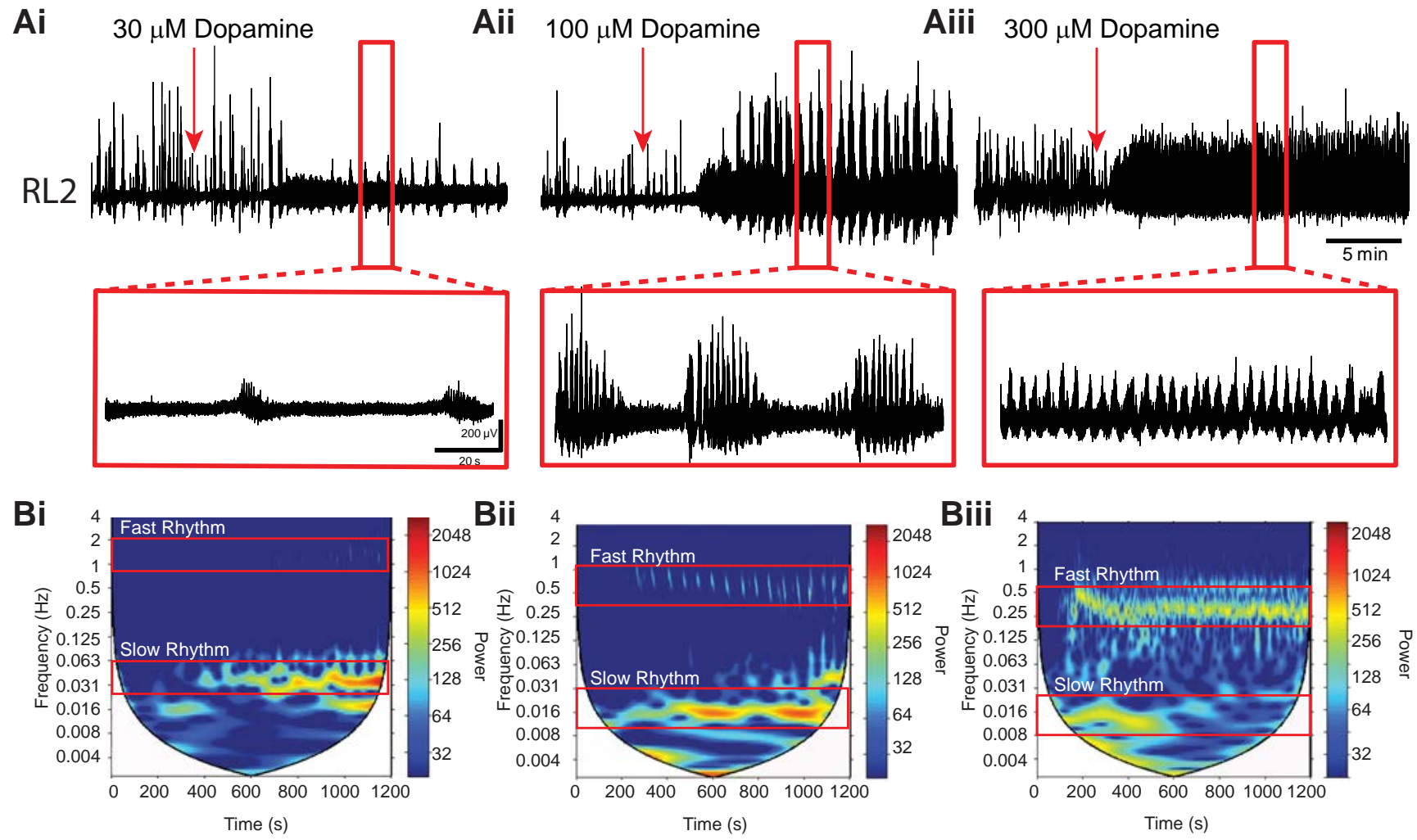

Fast Rhythm

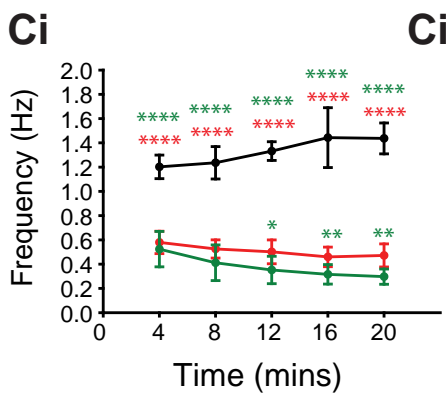

Cii
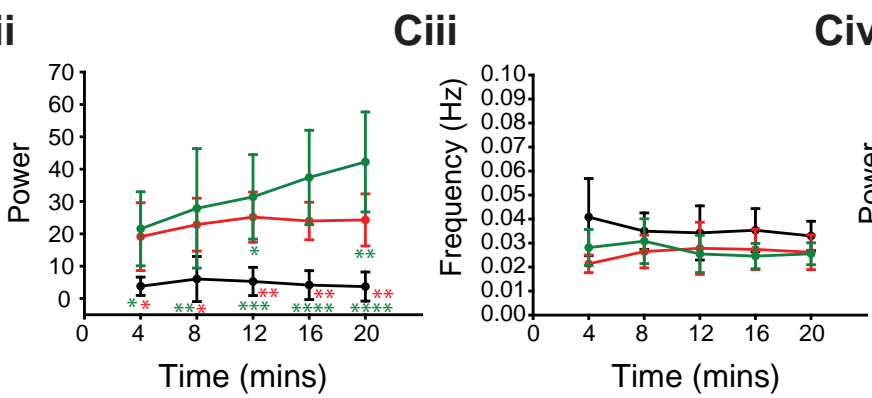

Slow Rhythm

Figure 2. High concentrations of dopamine evoke rhythmicity. Ai-Aiit, Neurograms from single $L 2$ ventral roots from individual experiments with dopamine (DA) bath applied (red arrows) at $30 \mu \mathrm{M}$ (Ai), $100 \mu \mathrm{M}$ (Aii), and $300 \mu \mathrm{M}$ (Aiii) to naive preparations evoke rhythmic motor activity. Bi-Biii, The fast and slow rhythms are illustrated in the autowavelet frequency power spectrograms over time with frequency on the left $y$-axis, time on the $x$-axis, and warmer colors representing higher power. Rhythm frequency and power of the fast and slow rhythms were analyzed by selecting regions of interest selected within bouts of the fast rhythm and within the range of the slow rhythm. Ci, Cii, The frequency of the fast rhythm slowed down $(\boldsymbol{C i})$ and power increased (Cii) with dopamine concentration. Ciii, Civ, No differences were found in frequency (Ciit) or power (Civ) of the slow rhythm between dopamine concentrations. Data are presented as the mean $\pm \mathrm{SD}$, with asterisks denoting significance $(* p<0.05, * * p<0.01$, $* * * p<0.001$ ) with Tukey post hoc test following a two-way ANOVA between time (5 min bins) and dopamine concentration.

\section{Statistics}

Repeated-measures ANOVAs were conducted for experiments that involved manipulation of the network excitation state after the addition of dopamine (i.e., $\mathrm{KCl}$ or NMDA). Tukey post hoc analyses were conducted when significant main effects were detected with $p<0.05$. One-way ANOVAs were performed for excitability reduction experiments. Post hoc analyses were performed comparing the frequency power for each experiment to frequency power of rhythms evoked by $50 \mu \mathrm{M}$ dopamine alone in previous experiments. Nonparametric Friedman repeated-measures ANOVA or Mann-Whitney rank sum tests were conducted when assumptions of normality or equal variance were violated using a Shapiro-Wilk test and a Brown-Forsythe test, respectively. Power analyses could not be conducted on nonparametric statistics.

\section{Results}

\section{Dopamine evokes multiple patterns of rhythmic motor activity}

We first examined the rhythmic activity evoked only by dopamine, a neuromodulator often used to modulate locomotor activity (Whelan et al., 2000; Bonnot et al., 2002; 
A $50 \mu \mathrm{M}$ Dopamine

$$
4 \mathrm{mM} \mathrm{KCl}
$$

$6 \mathrm{mM} \mathrm{KCl} \quad 8 \mathrm{mM} \mathrm{KCl} \quad 10 \mathrm{mM} \mathrm{KCl}$

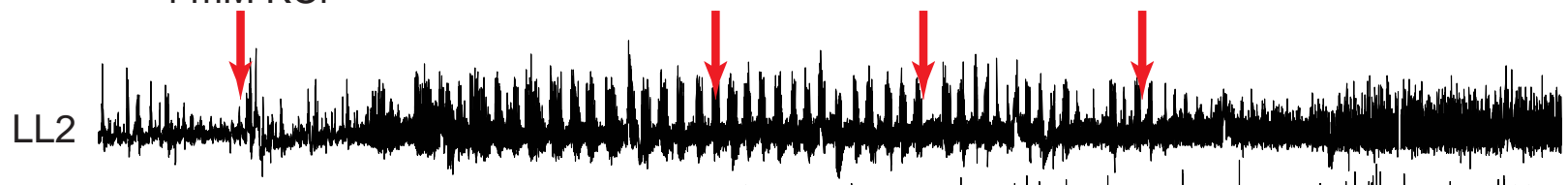

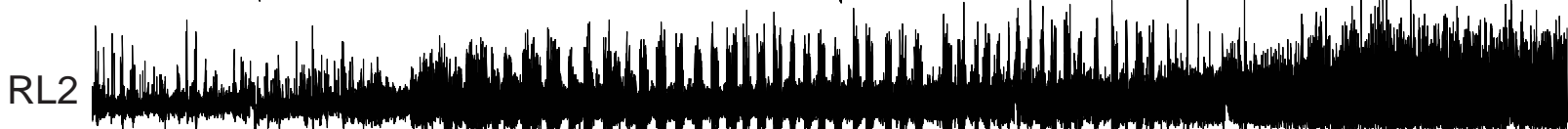

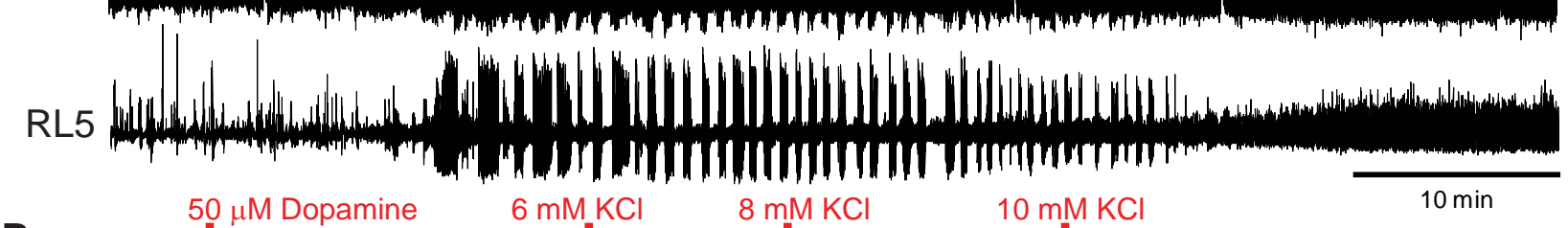

B

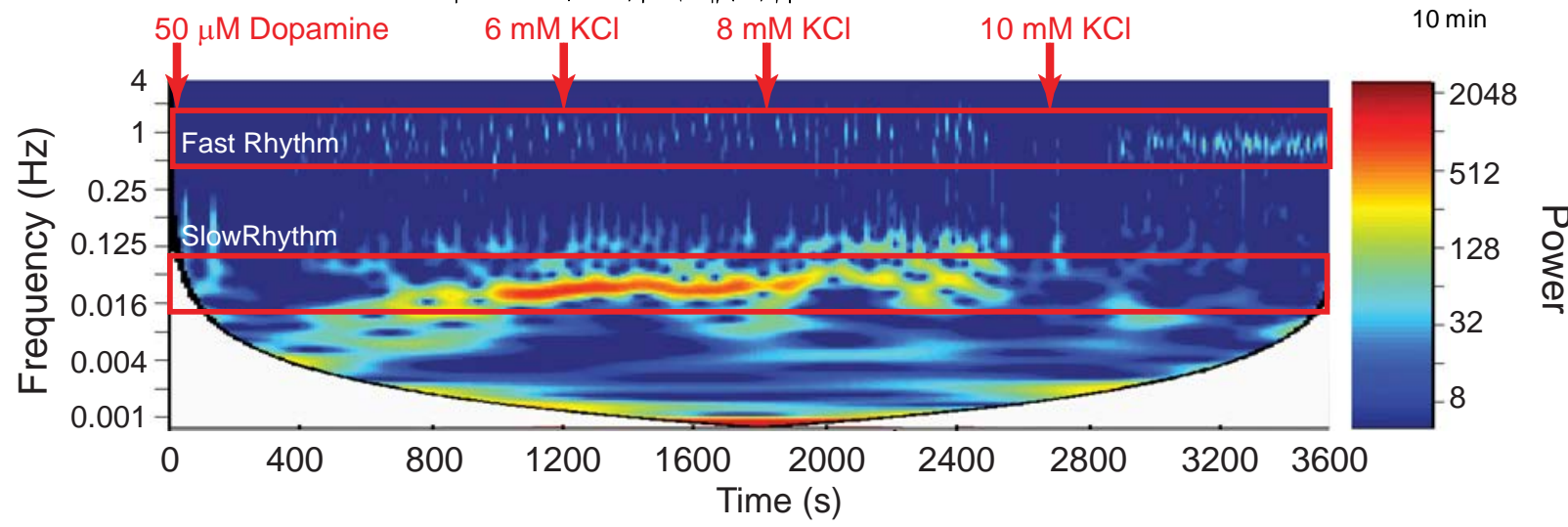

Ci

\section{$50 \mu \mathrm{M}$ Dopamine $4 \mathrm{mM} \mathrm{KCl}$}

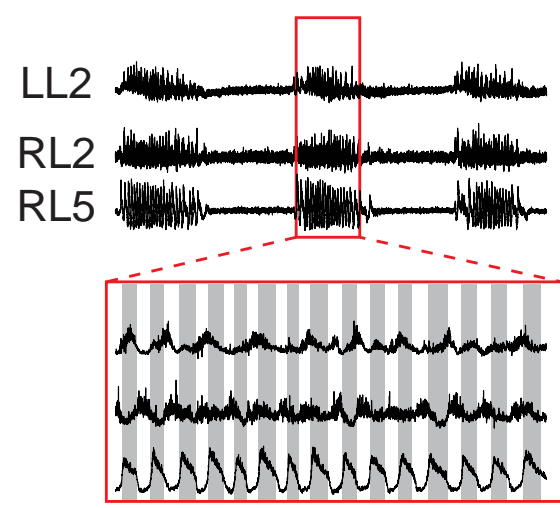

Cii

$50 \mu \mathrm{M}$ Dopamine $8 \mathrm{mM} \mathrm{KCl}$
Ciii
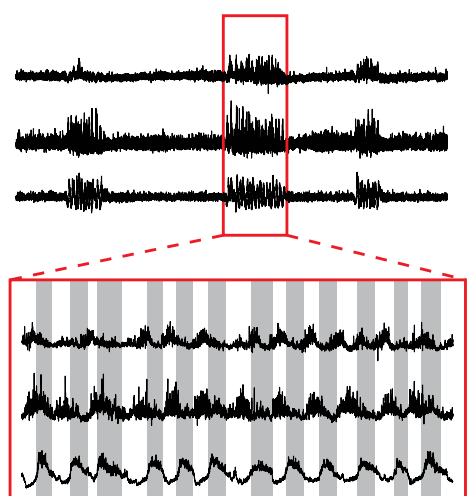

Ei
L2-L2 Fast Rhythm $330 \quad 0 \quad 30$
$50 \mu \mathrm{M}$ Dopamine $10 \mathrm{mM} \mathrm{KCl}$
Di Fast Rhythm

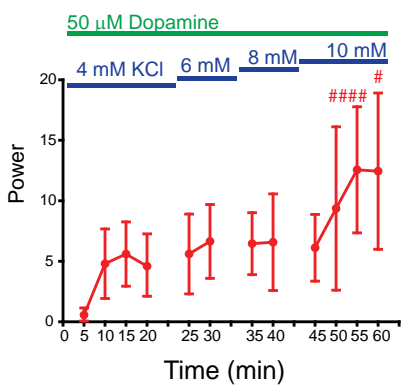

\section{Dii \\ Slow Rhythm}

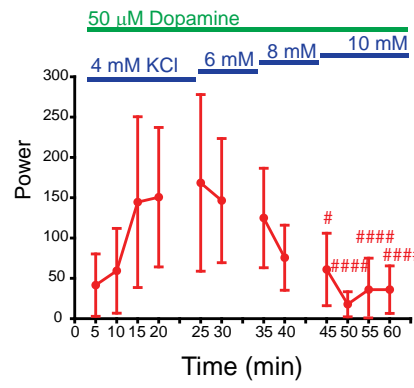

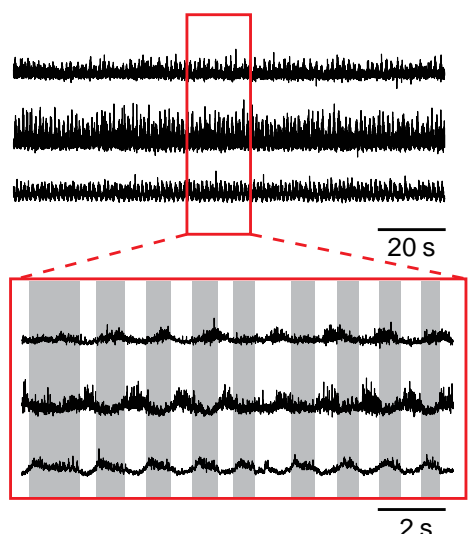

$\mathrm{Ei}$
iL2-L5 Fast Rhythm $330 \quad 0 \cdot 30$

Figure 3. Sequentially boosting network excitation with $\mathrm{KCl}$ modulates dopamine-evoked rhythmicity. $\boldsymbol{A}$, Neurograms recorded from the left and right L2 and right L5 ventral roots show raw data and the effect on rhythmicity. Bath application of $50 \mu \mathrm{m}$ dopamine evokes 


\section{continued}

a multirhythmic pattern of motor activity that is modulated as network excitation is boosted by sequentially increasing the concentration of $\mathrm{KCl}$ in the bath (red arrows). When $\mathrm{KCl}$ concentration is increased to $10 \mathrm{~mm}$, the pattern switches from multirhythmic to a single, continuous locomotor-like rhythm. $\boldsymbol{B}$, The frequency power distribution following dopamine application and subsequent excitability manipulation is illustrated in the cross-wavelet frequency power spectrogram over time with frequency on the left $y$-axis, time on the $x$-axis, and increasing power represented as warmer colors. At $10 \mathrm{~mm} \mathrm{KCl,} \mathrm{the} \mathrm{pattern} \mathrm{switches} \mathrm{from} \mathrm{multiple} \mathrm{rhythms}$ to a single continuous rhythm. $\boldsymbol{C i}$-Ciii, Representative neurograms showing rhythm at baseline (Ci), dopamine with 8 mm $\mathrm{KCl}(\boldsymbol{C i i})$, and a continuous locomotor-like rhythm expressed with dopamine and $10 \mathrm{~mm} \mathrm{KCl}$ (Ciii). $\boldsymbol{D}$, Regions of interest were selected around the fast and slow rhythms, and the respective frequency and power for left and right L2 and L5 neurograms were analyzed over time. Di, Dii, Increasing network excitation increased the power of the fast rhythm (Di) and decreased the power of the slow rhythm (Dii). Data are presented as the mean $\pm S D$, with asterisks denoting a significant difference between the respective point and the rhythm at 20 min following dopamine application $(* p<0.05$, $* * p<0.01$, ***p $<0.001$ ) obtained from Tukey post hoc analysis when significant main effects on a repeated-measures ANOVA were found. Nonparametric statistical analysis was performed when assumptions of normality failed, and significance was denoted as follows: \#p $<0.05$, \#\#p $<0.01$, \#\#\#p $<0.001$. Ei, Eii, The phase between L2 neurograms for the fast rhythm is presented in the circular plots in Ei and Eii and illustrate the switch to a locomotor-like pattern at $10 \mathrm{~mm} \mathrm{KCl}$ as the vector length increases and phase moves toward $180^{\circ}$ (alternating) in both the left and right L2s and ipsilateral L2-L5. Each dot represents the average phase for an individual preparation for each respective experimental condition. The length of the arrows represents the mean vector length $(r)$ or the robustness of the pattern.

Barrière et al., 2004; Humphreys and Whelan, 2012; Sharples et al., 2015; Picton et al., 2016). The rhythm that emerged following bath application of $50 \mu \mathrm{M}$ dopamine does not resemble a fictive locomotor pattern, which is typically characterized by continuous and alternating bursts between left and right sides within segments and alternation between ipsilateral L2 and L5 bursts. Instead, the rhythm evoked by dopamine consists of a slow and a fast component. The slow episodes occurred synchronously across left and right ventral roots in the L2 (phase: 20.5 $; r=0.89 ; p<0.0001$ ) and L5 (phase: $16.4^{\circ} ; r=$ $0.87 ; p<0.0001$; Fig. 1A,EI) and between ipsilateral ventral root bursts in the L2 and L5 (phase: $14.0^{\circ} ; r=$ $0.91 ; p<0.0001$ ). The bouts had a mean cycle period of $50 \pm 15 \mathrm{~s}$ (Fig. 1Di) with the onset phase locked across $L 2$ and L5 bursts. Episode durations are significantly longer in L2 segments compared to L5 possibly reflecting a rostrocaudal gradient of excitability for dopamine (Christie and Whelan, 2005; Fig. 1Dii; L2, $30.5 \pm 19$ s; L5, $23.0 \pm$ $7.9 \mathrm{~s}$; Wilcoxon signed rank test: $\mathrm{W}=-160, \mathrm{~T}+=25, \mathrm{~T}-$ $=-185, z=-2.99, p=0.002)$. The slow rhythm can be observed in the high power region within the frequencypower spectrogram around $0.02 \mathrm{~Hz}$ (Fig. 1C).

The slow-depolarizing episodes activated a faster rhythm that was superimposed on the episodes and is illustrated in the fast rhythm band in Figure 1B. In both the L2s and the L5s, the fast rhythm slows from $1.1 \pm 0.3$ to $0.83 \pm 0.2 \mathrm{~Hz}$ over the course of the episode (Fig. 1Diii; L2: $t_{(18)}=4.9, p<0.00006$; L5: $\left.t_{(18)}=4.9, p=0.00005\right)$ with no change in rhythm power over the course of an episode and no difference in power between L2 and L5 segments (Fig. 1Div). We found instances when the pattern of bursts between ventral root neurograms of left and right L2, left and right L5, or ipsilateral L2-L5 pairs within the fast rhythm start off synchronous and switched to an alternating pattern toward the end of the episode (Fig. 1Eii). There are also episodes where the fast rhythm is either alternating or synchronous between root pairs for the duration of the episode. Of note, the pattern never started off alternating and changed to synchrony. Examination of the fast rhythm in all episodes in the left and right L2 neurograms revealed that the predominant pat- tern consists of a fast rhythm that starts off alternating and finishes alternating ( $54.5 \%$ of episodes). This is in contrast to the predominant pattern of bursting between ipsilateral L2 (iL2) and iL5 left-right (L-R) L5, which started off as synchronous and ended as synchronous (iL2-L5, $51.8 \%$ of bursts; L-R L5, $85.8 \%$ of episodes; Fig. 1Eiii). The predominant burst pattern within each ventral root pair is reflected in the mean vector plots when the data from all episodes are averaged as the average pattern is alternating within the L2s (Fig. 1Fi; phase: $154.4^{\circ} ; r=$ 0.65 ; Rayleigh test, $p=0.0001$ ), synchronous in the L5s (phase: $20.3^{\circ} ; r=0.72$; Rayleigh test, $p=0.00002$ ), and biased toward synchrony in the ipsilateral L2-L5s (Fig. 1Fii; phase: $78.6^{\circ} ; r=0.45 ; p=0.02$ ).

Different patterns of rhythmic motor activity were expressed at different concentrations of dopamine tested in a series of experiments (Fig. 2). Recording from single L2 ventral roots, we determined that $30 \mu \mathrm{M}$ was the lowest concentration of dopamine capable of evoking rhythmicity in five of eight preparations. A $100 \mu \mathrm{M}$ concentration evoked robust discontinuous multirhythmic activity (seven of nine preparations) or even weak continuous rhythmicity (two of nine preparations), and a $300 \mu \mathrm{M}$ concentration evoked robust continuous patterns of rhythmicity (six of eight preparations). In rhythmic preparations, the time from the addition of dopamine until the first bout of rhythmicity decreased as a function of dopamine concentration $(30 \mu \mathrm{M}=562 \pm 173 \mathrm{~s} ; 100 \mu \mathrm{M}=338 \pm 70 \mathrm{~s} ; 300 \mu \mathrm{M}=$ $231 \pm 46 s ; p<0.001)$. The frequency of the fast rhythm was significantly higher at $30 \mu \mathrm{M}$ compared with 100 and $300 \mu \mathrm{M}$ (Fig. 2Ci; $F_{(2,19)}=186 ; p<0.001$ ). The fast rhythm slowed down and became more robust (greater power) as a function of dopamine concentration (Fig. 2 Cii; $\left.F_{(2,19)}=20.33 ; p<0.001\right)$ as the rhythm switched from a multirhythm at $100 \mu \mathrm{M}$ to a continuous rhythm at $300 \mu \mathrm{M}$.

\section{Dopamine-evoked rhythmicity is dependent on network excitation state}

The position of the network within parameter state space has been proposed to affect how neuromodulators influence rhythmic motor network output (Marder et al., 
A

$10 \mathrm{mM}$

$\mathrm{KCl}$
$50 \mu \mathrm{M}$

Dopamine
Wash

$50 \mu \mathrm{M}$ Dopamine

+ $4 \mathrm{mM} \mathrm{KCl}$

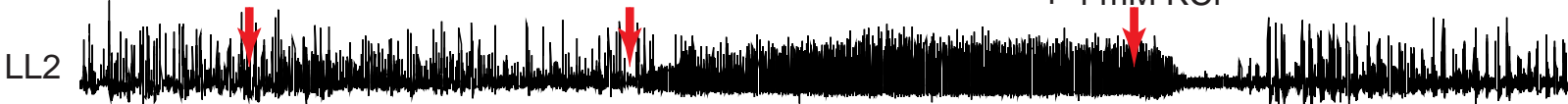

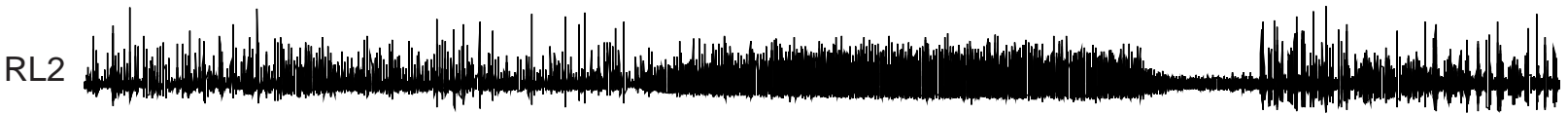

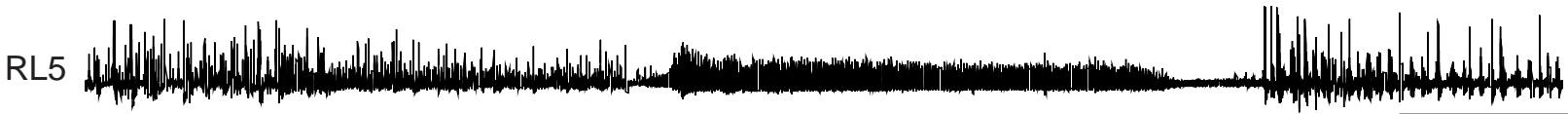

B

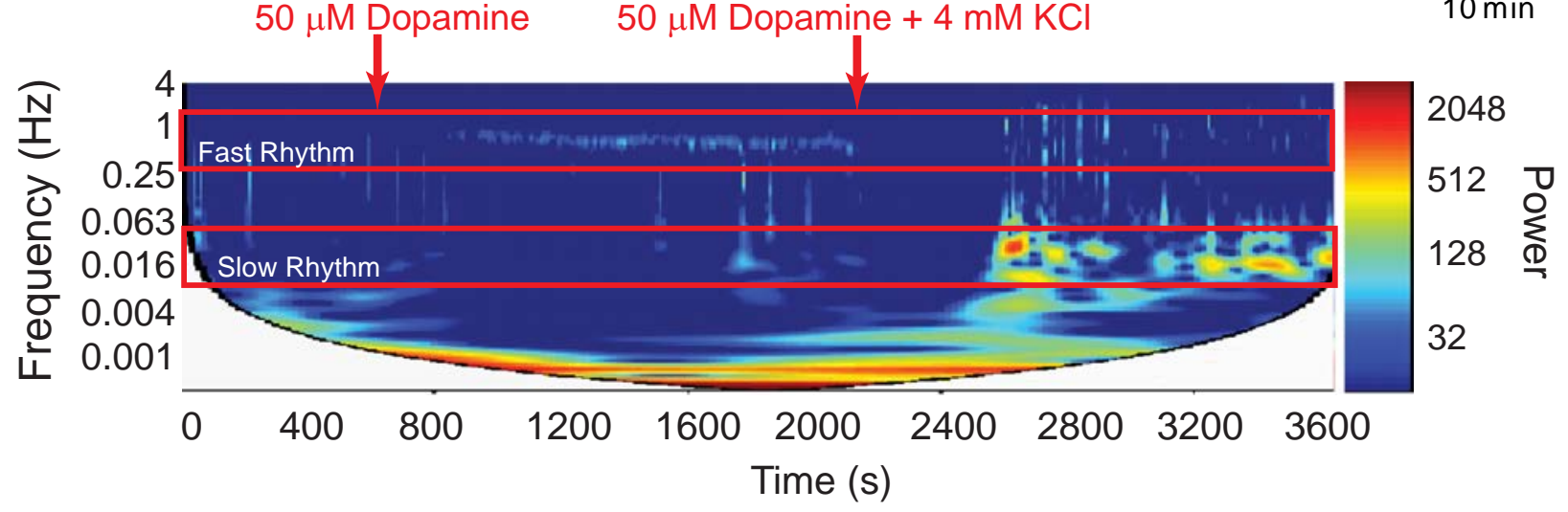

Ci

$50 \mu \mathrm{M}$ Dopamine $10 \mathrm{mM} \mathrm{KCl}(600 \mathrm{~s})$
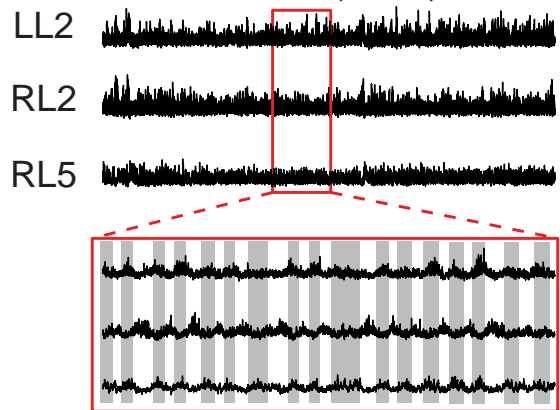

Cii $\quad 50 \mu \mathrm{M}$ Dopamine $10 \mathrm{mM} \mathrm{KCl}$ (1200 s)
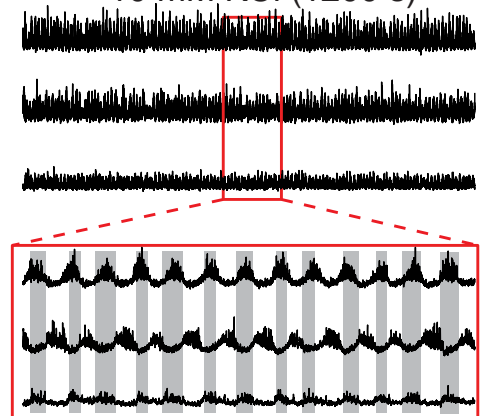

Ciii $50 \mu \mathrm{M}$ Dopamine $4 \mathrm{mM} \mathrm{KCl}$ (3200 s)
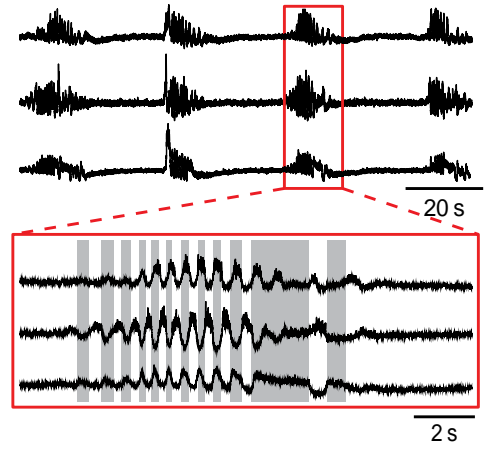

Di

Fast Rhythm

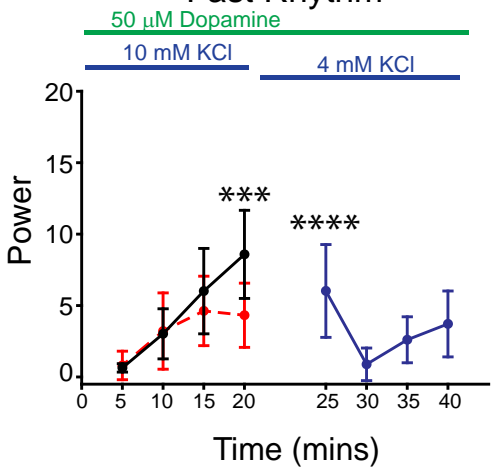

Dii

Ei Slow Rhythm

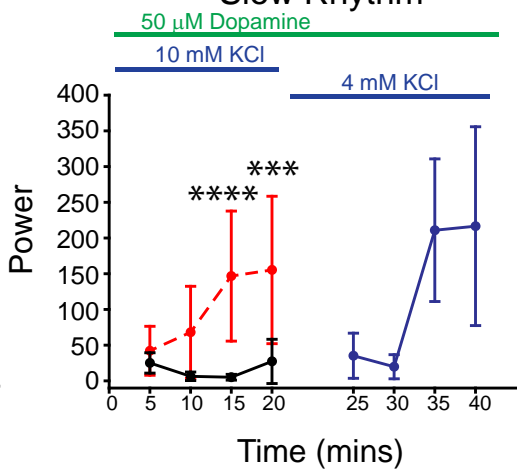

Eii L2-L2 Fast Rhythm iL2-L5 Fast Rhythm
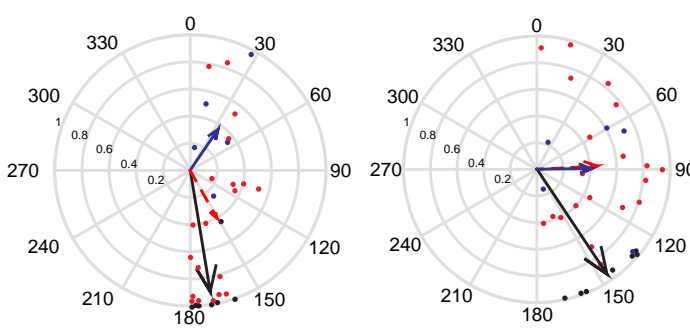

. - . - . Expected (4 mM KCl)

$-10 \mathrm{mM} \mathrm{KCl}$

\section{Wash out $4 \mathrm{mM} \mathrm{KCl}$}

Figure 4. Boosting network excitation with $\mathrm{KCl}$ prior to the application of dopamine evokes locomotor-like rhythmicity. $\boldsymbol{A}$, Neurograms recorded from left and right $L 2$ and right $L 5$ ventral roots illustrate the experimental paradigm and the resultant effect on rhythmicity. 


\section{continued}

$\mathrm{KCl}$ concentration was increased to $10 \mathrm{~mm}$ to boost network excitation 20 min prior to application of $50 \mu \mathrm{M}$ dopamine (DA). Subsequent application of DA resulted in the direct expression of a continuous locomotor-like rhythm that returned to a multirhythm when washed out with regular $(4 \mathrm{~mm} \mathrm{KCl})$ aCSF and $50 \mu \mathrm{m} \mathrm{DA}$. $\boldsymbol{B}$, Frequency power spectrogram with frequency on the left $y$-axis, time on the $x$-axis, and increasing power represented as warmer colors. Ci, Cii, Raw data showing zoomed regions represented in $\boldsymbol{B}$ of $50 \mu \mathrm{m}$ dopamine plus $10 \mathrm{~mm} \mathrm{KCl}$ at a longer time point $(\boldsymbol{C} \boldsymbol{i})$ and following wash in of $4 \mathrm{~mm} \mathrm{KCl}(\boldsymbol{C i i})$. D, Region-of-interest analysis of fast and slow rhythms within L2 root pairs illustrate significantly higher power of the fast rhythm with $10 \mathrm{~mm} \mathrm{KCl}$ compared with the expected rhythm power at $4 \mathrm{~mm} \mathrm{KCl}$. Di, The slow rhythm showed significantly lower power compared with the expected multirhythm evoked in the $4 \mathrm{~mm} \mathrm{KCl}$ condition. Dii, The expected power values returned to the same level as the expected condition following a washout with $4 \mathrm{~mm} \mathrm{KCl}$ (Blue lines). Ei, Eii, Circular plots in Ei and Eii illustrate a locomotor-like pattern with vector length increases accompanied by phase angles moving toward $180^{\circ}$ (alternating) in both the left and right L2s and ipsilateral L2-L5 at higher $\mathrm{KCl}$ concentrations. The length of arrows represents mean vector length $(r)$ and angle or robustness of the pattern. Red lines represent mean data ( $n=20$ preparations) when $50 \mu \mathrm{M}$ DA (aCSF, $4 \mathrm{~mm} \mathrm{KCl)} \mathrm{was} \mathrm{applied,} \mathrm{and} 20$ min of baseline data were analyzed. Black lines represent the rhythm evoked by $50 \mu \mathrm{M}$ DA under enhanced network excitation (aCSF, $10 \mathrm{~mm} \mathrm{KCl}$ ), and blue lines represent the washout condition of DA (aCSF, $4 \mathrm{~mm} \mathrm{KCl)}$ ). Each dot in the phase plots represents the average phase for an individual preparation for each respective experimental condition. Data are presented as the mean \pm SD. A two-way ANOVA between each excitability condition (DA-evoked rhythm in $4 \mathrm{~mm} \mathrm{KCl}, 10 \mathrm{mM} \mathrm{KCl}$, and washing with $4 \mathrm{~mm} \mathrm{KCl}$ ) and time to examine the effects of manipulating network excitation prior to DA application. When significant main effects of interactions were detected Tukey post hoc analysis between time-matched points following DA application were conducted. Asterisks denote significance, as follows: $* p<0.05, * * p<$ $0.01, * * * p<0.001$

2014) and may contribute to the variability we observed with respect to the diversity in rhythmic patterns evoked at different dopamine concentrations. Conceptually, if a neuromodulator is acting around the transition point for a network, where the pattern would change, a similar change in intrinsic properties of a class of neurons within the network would have a large effect compared with when it operates far from the transition borders. We therefore devised a series of experiments whereby the global excitability of spinal motor networks was manipulated by increasing the concentration of extracellular $\mathrm{KCl}$ in the bath or by application of NMDA to nonspecifically excite spinal motor networks. The goal here was to move the spinal network around a state space so that we would abut transition zones.

Following bath application of $50 \mu \mathrm{M}$ dopamine and the generation of a regular multirhythm, the bath $\mathrm{KCl}$ concentration was sequentially increased from basal levels $(4 \mathrm{mM}$ $\mathrm{KCl}$ in the aCSF) in $2 \mathrm{mM}$ increments, and the resultant effects on the rhythm were recorded (Fig. $3 ; n=10$ ). The duration of the episodes that composed the slow rhythm decreased as $\mathrm{KCl}$ was increased, and differences in episode duration in L2 and L5 were no longer apparent at 6 and $8 \mathrm{mM} \mathrm{KCl}$ (baseline: L2, $31 \pm 26 \mathrm{~s}$; L5, $23.6 \pm 9.5 \mathrm{~s}$; 6 mM: L2, $17.7 \pm 5 \mathrm{~s} ;$ L5, $15.0 \pm 2.5 \mathrm{~s} ; 8$ mM: L2, $12.4 \pm$ $2.4 \mathrm{~s} ; \mathrm{L} 5,11.8 \pm 2.3 \mathrm{~s}$ ). Boosting network excitation via $\mathrm{KCl}$ decreased the frequency of the fast rhythm (L2: $\left.F_{(11,99)}=5.9, p<0.001 ; \mathrm{L} 5: F_{(11,88)}=0.47, p=0.9\right)$ and increased the frequency of the slow rhythm $\left(\mathrm{L} 2: F_{(11,99)}=\right.$ $3.7, p<0.001)$ in the L2s. The power of the fast rhythm increased (L2: $\chi_{(11)}^{2}=53.7, p<0.001 ;$ L5: $\chi_{(11)}^{2}=51.2$, $p<0.001)$, and slow rhythm decreased (L2: $\chi^{2}(11)=63.8$, $p<0.001$; L5: $\left.F_{(10,80)}=8.3, p<0.001\right)$ in both the L2s and L5s (Fig. 3Di,Dii) as excitation was increased and is a reflection of the rhythm switching from discontinuous multirhythm to a continuous rhythm. The pattern of the fast rhythm became more locomotor like as excitation was increased, which is indicated by the phase moving toward $180^{\circ}$ in the left and right L2s (Fig. 3EI), the ipsilateral L2 and L5 (Fig. 3Eii), and the left and right L5s (DA baseline: phase, $13.5^{\circ}, r=0.75, p=0.004 ; 10 \mathrm{~mm} \mathrm{KCl}$ : phase, $145^{\circ}, r=0.43, p=0.2$ ).

These effects were replicated when network excitation was enhanced by the addition of $10 \mathrm{~mm} \mathrm{KCl}$ prior to the application of $50 \mu \mathrm{M}$ dopamine (Fig. 4Di,Dii; $n=7$; L2 power: fast rhythm, $F_{(1,100)}=7.4, p=0.008$; slow rhythm, $\left.F_{(1,100)}=33.6, p<0.0001\right)$. No rhythmicity was observed at $10 \mathrm{~mm} \mathrm{KCl}$ alone; however, the addition of $50 \mu \mathrm{M}$ dopamine evoked a continuous locomotor-like rhythm with alternation in the left and right L2 and L5 and the ipsilateral L2-L5, with no transition through a multirhythmic pattern (Fig. 4Ei,Eii; L2-L2 phase: $170^{\circ} ; r=0.91$; Rayleigh test, $p=0.0009$; L5-L5 phase: $157^{\circ} ; r=0.72$; Rayleigh test, $p=0.02$; iL2-L5 phase: $146^{\circ} ; r=0.95 ; p=$ $0.0003)$. This reverted back to a multirhythm with a wash in of $50 \mu \mathrm{M}$ dopamine with regular $(4 \mathrm{mM} \mathrm{KCl})$ aCSF with no significant difference in fast or slow rhythm power under the wash conditions compared with the expected basal rhythm power (Fig. 4Di,Dii; $n=5$; L2 power: fast rhythm, $F_{(1,92)}=1.3, p=0.25$; slow rhythm, $F_{(1,92)}=0.78$, $p=0.4$ ). These data indicate that there were no significant order effects due to sequential administration of $\mathrm{KCl}$ or second-messenger desensitization effects with time.

In a complimentary set of experiments, following the generation of a robust multirhythm, network excitation was reduced by washing in $50 \mu \mathrm{M}$ dopamine in aCSF with $1 \mathrm{mM} \mathrm{KCl}$ (Fig. 5A). As expected, the power of the fast rhythm degraded in the L2s (Fig. $5 F ; n=6 ; p=0.02$ ) and a trend toward reduced power the L5s (Fig. 5Fii, $n=5 ; p$ $=0.06$ ) with no significant reduction in the slow rhythm (Fig. 5Fiii,Fiv). Similarly, $50 \mu \mathrm{M}$ dopamine had a qualitatively smaller effect on network dynamics when it was presumably far from a transition point, as it did not evoke a fast rhythm when preparations were recovered in aCSF with $1 \mathrm{mM} \mathrm{KCl}$ for $1 \mathrm{~h}$ prior to dopamine application (Fig. $5 B$,Fi,Fii; L2, $p<0.001$; L5, $p=0.004$ ). In both experiments, the rhythm was slightly recovered by washing in regular aCSF (4 mM KCl; Fig. $5 A, B$ ).

Manipulating the extracellular $\mathrm{KCl}$ concentration also affects chloride concentrations. We reproduced the 
$4 \mathrm{mM} \mathrm{KCl}+50 \mu \mathrm{M}$ Dopamine $1 \mathrm{mM} \mathrm{KCl}+50 \mu \mathrm{M}$ Dopamine

A

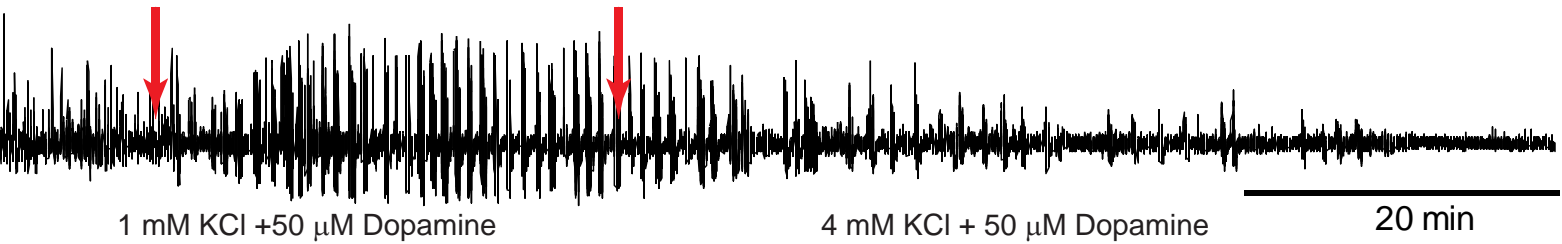

B $1 \mathrm{mM} \mathrm{KCl}+50 \mu \mathrm{M}$ Dopamine

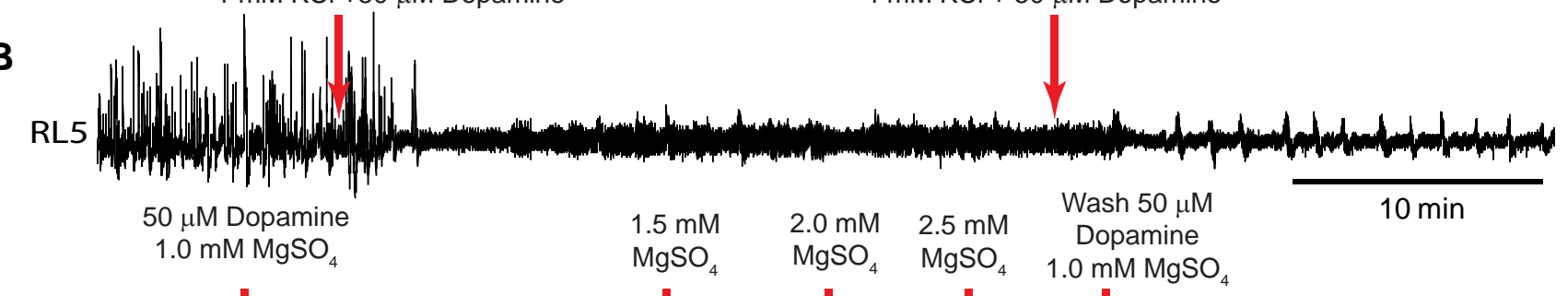

C

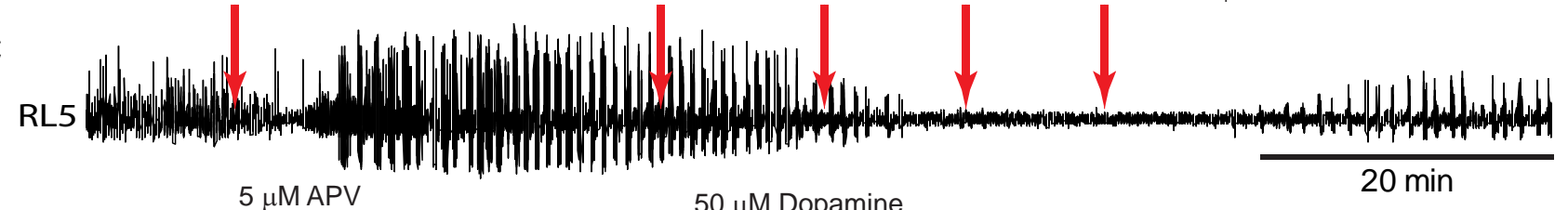

D

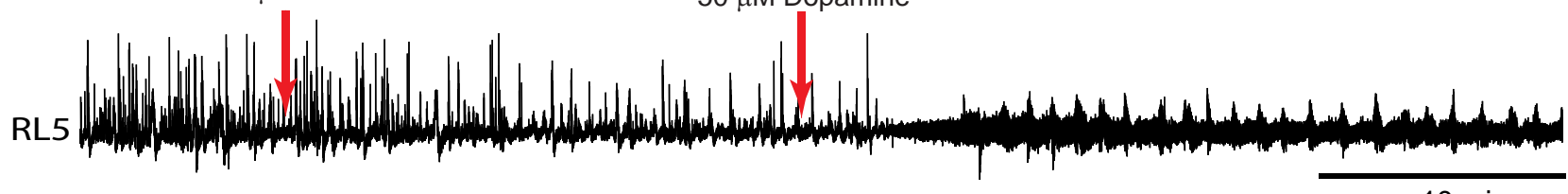

$\mathbf{E}$

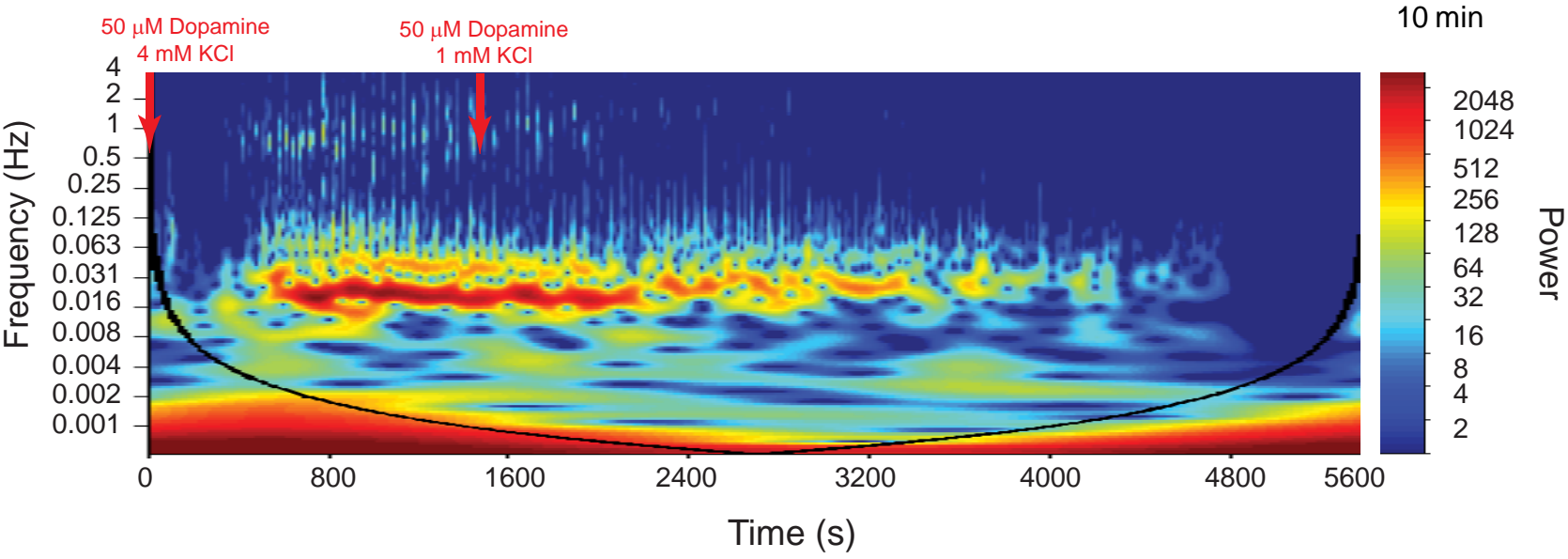

Fast Rhythm
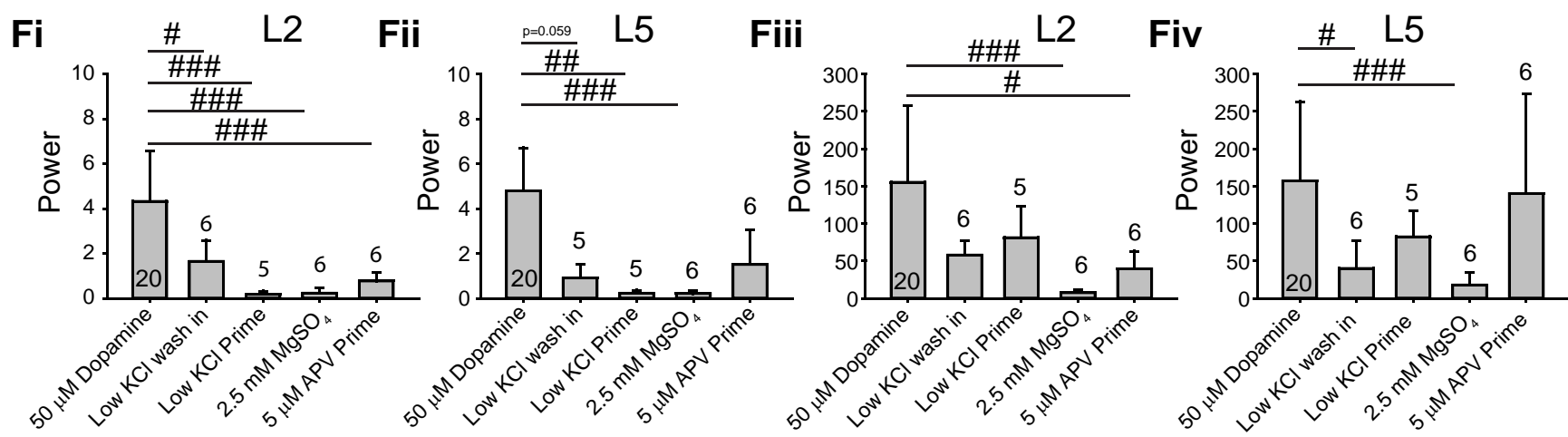

Figure 5. Decreasing network excitation disrupts the ability of dopamine to evoke rhythmicity. $\boldsymbol{A}-\boldsymbol{D}$, Neurograms from single ventral roots within the L5 illustrate the overall effect of reducing network excitation via several pharmacological approaches on dopamineevoked rhythmicity. $\boldsymbol{A}$, In the first experiment, network excitability was reduced by washing in aCSF containing $1 \mathrm{~mm}$ KCl after evoking a rhythm. $\boldsymbol{B}$, In a second experiment, preparations were recovered in low $\mathrm{KCl}(1 \mathrm{~mm})$ aCSF for $1 \mathrm{~h}$ prior to dopamine application. $\boldsymbol{C}$, 
continued

In a third experiment, excitability was reduced by sequentially increasing bath $\mathrm{MgSO}_{4}$ concentration (1.0-2.5 mM) after evoking a rhythm with dopamine. $\boldsymbol{D}$, In a final experiment, AP5 was bath applied to antagonize NMDA receptors $(5 \mu \mathrm{M}) 20 \mathrm{~min}$ prior to the addition of dopamine. $\boldsymbol{E}$, An example cross-wavelet frequency power spectrogram illustrates the degradation of rhythmic activity when aCSF with dopamine and low $\mathrm{KCl}$ washed into the bath. $\boldsymbol{F}$, Regions of interest were analyzed for cross-wavelet spectrograms between left and right L2 and L5 neurograms around fast and slow rhythm frequency bands. Fi, Fii, The power of the fast rhythm was reduced under all conditions in the L2 (Fi) and L5 (Fii) neurograms. Fiv, Slow rhythm power was reduced in the L2s but was reduced only in the $\mathrm{L} 5 \mathrm{~s}$ by $\mathrm{MgSO}_{4}$ and washing in low $\mathrm{KCl}$. Data are presented as the mean $\pm \mathrm{SD}$, with asterisks denoting a significant difference between the respective point and the rhythm at 20 min following dopamine application. Nonparametric one-way ANOVAs were performed for fast or slow rhythms in L2 and L5 power. Significant differences on post hoc analyses between each respective condition compared to rhythm power from $50 \mu \mathrm{m}$ dopamine alone (\#p $<0.05$, \#\#p $<0.01$, \#\#\#p $<0.001$ ).

above experiments using NMDA to increase excitability across neuronal populations using concentrations (2-6 $\mu \mathrm{M})$ subthreshold to those that evoke rhythmicity on their own (Fig. 6; $n=10$ ). The duration of the episodes that compose the slow rhythm decreased as NMDA was increased, and differences in episode duration in L2 and L5 were no longer apparent at 2 and $4 \mu \mathrm{M}$ NMDA (baseline: L2, $29 \pm 9.5$ s; L5, $22.6 \pm 6.5$ s; $2 \mu \mathrm{M}$ : L2, $19.4 \pm 7$ s; L5, $17.2 \pm 4.1 \mathrm{~s} ; 4 \mu \mathrm{M}:$ L2, $13.2 \pm 4.3 \mathrm{~s} ; \mathrm{L} 5,12.6 \pm 4.5 \mathrm{~s})$. Boosting network excitation via NMDA decreased the frequency of the fast rhythm $\left(\right.$ L2: $\chi_{(11)}^{2}=64.3, p<0.001$; L5: $\left.F_{(11,99)}=8.8, p<0.001\right)$ and increased the frequency of the slow rhythm $\left(\mathrm{L} 2: \chi^{2}{ }_{(11)}=22.2, p<0.05\right.$; L5: $F_{(11,99)}$ $=18.2, p<0.001)$ in the L2s and the L5s. The power of the fast rhythm increased (Fig. 6Di; L2: $\mathrm{X}^{2}{ }_{(11)}=82.7, p<$ 0.001 ; L5: $\left.F_{(11,99)}=12.1, p<0.001\right)$ and the slow rhythm decreased in both the L2s and L5s (Fig. 6Dii; L2: $\chi_{(11)}^{2}=$ $66.7, p<0.001$; L5: $\left.\chi_{(11)}^{2}=46.6, p<0.001\right)$ as excitation was increased, reflecting the rhythm switching from discontinuous multirhythm to a continuous rhythm. Likewise, the pattern of the fast rhythm became more locomotor like, as indicated by an increase in the mean vector length (r) pointing toward $180^{\circ}$ (alternating) in the left and right L2s (Fig. 6Ei), the ipsilateral L2 and L5 (Fig. 6Eii), and the left and right L5s (DA baseline: L5-L5 phase: $16.1^{\circ}, r=$ $-0.7, p=0.005 ; 6 \mu \mathrm{M}$ NMDA: L5-L5 phase: $113^{\circ}, r=$ $0.42, p=0.2)$.

In an additional set of experiments, during rhythmic activity evoked by dopamine, network excitation was progressively reduced by incrementally increasing the concentration of $\mathrm{Mg}^{2+}$ in the bath $\left(\mathrm{MgSO}_{4}\right)$. Increasing extracellular $\mathrm{Mg}^{2+}$ reduces the efficacy of NMDA-mediated synaptic transmission that is necessary for rhythmogenesis in the spinal cord (Soffe and Roberts, 1989) by impairing the removal of the voltage-dependent $\mathrm{Mg}^{2+}$ block in the NMDA channel. This manipulation was thus used as a means of reducing global network excitation by reducing the efficacy of excitatory synaptic transmission. A sequential increase in $\mathrm{Mg}^{2+}$ concentration from basal levels (1.0 mM) to $1.5 \mathrm{~mm}$ progressively degraded the multirhythm and fully disrupted rhythmic activity at $2.0 \mathrm{~mm}$, as reflected in a significant reduction in the power of both the fast rhythm (Fig. 5C,Fi,Fii; $n=6$; L2, $p<0.001$; L5, $p<0.001$ ) and the slow rhythm (Fig. 5Fiii,Fiv; $n=6$; L2, $p<0.001$; L5, $p<$ 0.001 ) in both the L2s and L5s. Subsequent experiments where NMDA channels were antagonized with a low concentration of APV $(5 \mu \mathrm{M})$ also inhibited the fast rhythm ( $n$ $=6, p<0.001)$ and the slow rhythm $(n=6, p=0.03)$ in the L2s but not the fast rhythm (Fig. 5D,Fi,Fii; $n=6, p=$ 0.1 ) or the slow rhythm (Fig. $5 D$,Fiii,Fiv; $n=6, p=0.7$ ) in the L5s.

\section{5-HT-evoked rhythmicity is also influenced by network excitation}

The above experiments describe how network excitation state influences the modulatory effect of dopamine on spinal motor output. Multirhythmic patterns of motor activity have been reported to be generated by a number of modulators, including noradrenaline, trace amines (Gozal et al., 2014), and 5-HT (MacLean et al., 1998; Schmidt et al., 1998). We next examined the generalizability of state dependency using 5-HT instead of dopamine. Examination of the frequency power spectrum over time following the application of low concentrations of 5-HT reveals that it too, although qualitatively different than dopamine, exhibits a slow underlying rhythm that is most apparent in the L2s and disappears as the concentration is increased (Fig. 7A). If this slow rhythm is a network phenomenon that is expressed at intermediate levels of excitation, then it should disappear as network excitation increases. To test this hypothesis, we sequentially increased network excitation in $2 \mathrm{mM} \mathrm{KCl}$ increments following the application of $15 \mu \mathrm{M} 5-\mathrm{HT}$, which was the most effective at evoking both slow and fast rhythms simultaneously. As expected, $\mathrm{KCl}$ increased the robustness of the fast, locomotor-like rhythm (Fig. 7Di; $n=5$; L2: $F_{(4,43)}=5.2, p<0.001$; L5: $\left.F_{(4,44)}=13.9, p<0.001\right)$ and decreased the power of the slow rhythm (Fig. 7Dii; $n=5$; L2: $F_{(4,43)}=4.6, p<$ 0.001 ; L5: $\left.\chi_{(11)}^{2}=31.1, p<0.001\right)$ up to $8 \mathrm{~mm} \mathrm{KCl}$, with a $10 \mathrm{~mm}$ concentration causing a shift to tonic activity and a resultant decline in the power of both the fast and slow rhythms (Fig. 7Di,Dii).

\section{Discussion}

Neuromodulators play a critical role in sculpting network behavior, but these effects are state dependent (Marder et al., 2014). We made use of a well defined mouse model to explore how network excitation state dictates the modulatory effects of dopamine on spinal locomotor circuits. When we moved the excitation state of the network, we found four stable zones where dopamine produced discrete network behaviors (Fig. 8). While dopamine was used here, our work suggests that these findings are relevant to other modulators such as serotonin, and this generalizability has been pointed out in 
A $\quad 50 \mu \mathrm{M}$ Dopamine

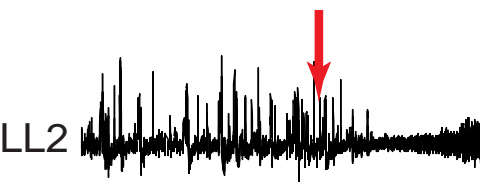

$2 \mu \mathrm{M}$

NMDA
$4 \mu \mathrm{M}$

NMDA
$6 \mu \mathrm{M}$

NMDA

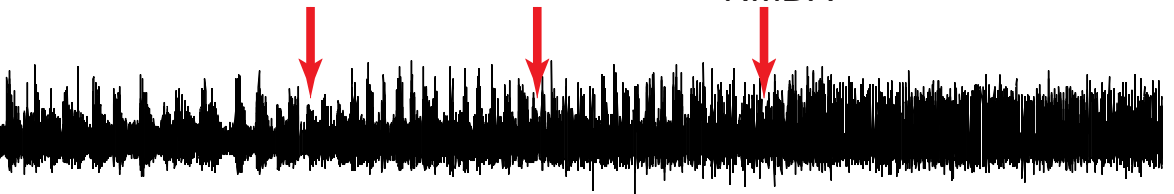
R2.

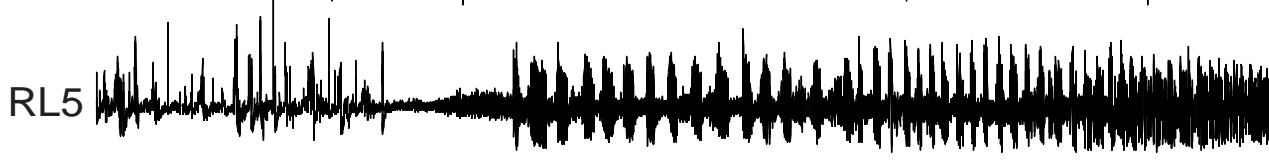

B

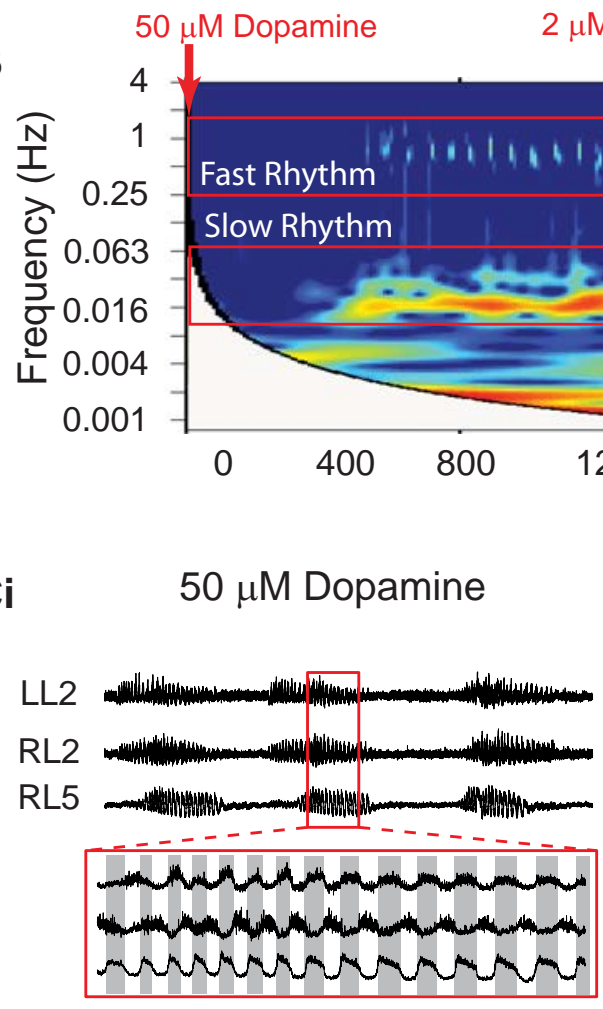

$\mu \mathrm{M}$ NMDA $4 \mu \mathrm{M}$ NMDA $6 \mu \mathrm{M}$ NMDA

$10 \min$

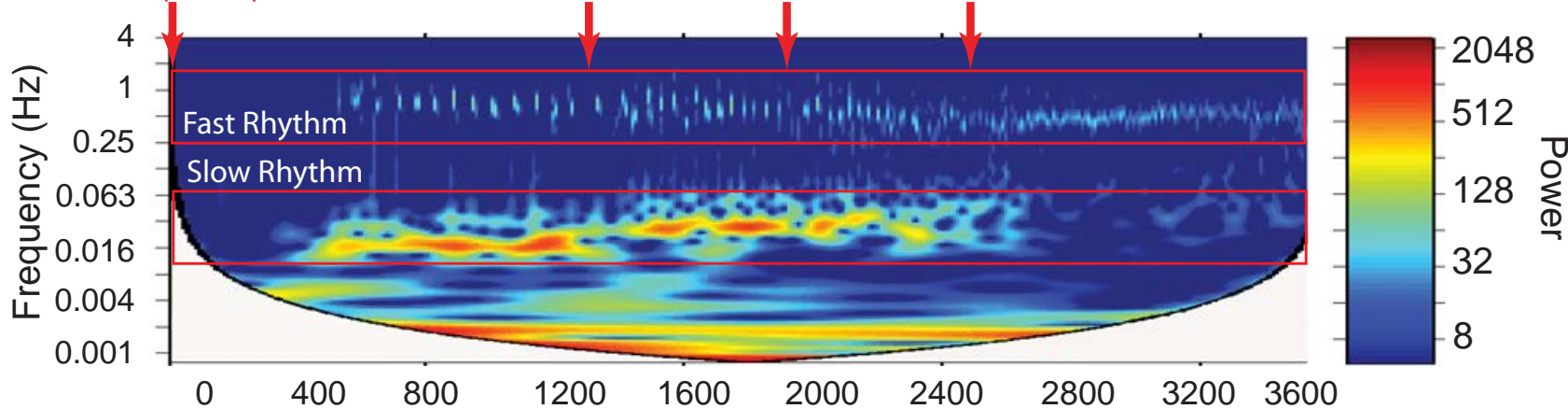

Time (s)

Di

Fast Rhythm

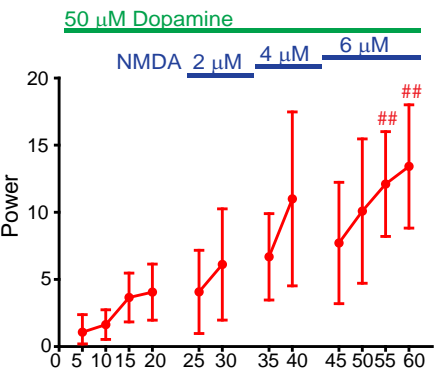

Time (mins)
Dii

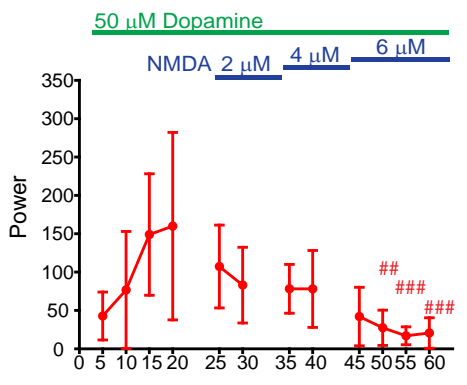

Time (mins)
Ciii $\quad 50 \mu \mathrm{M}$ Dopamine $6 \mu \mathrm{M}$ NMDA $4 \mu \mathrm{M}$ NMDA

Ei

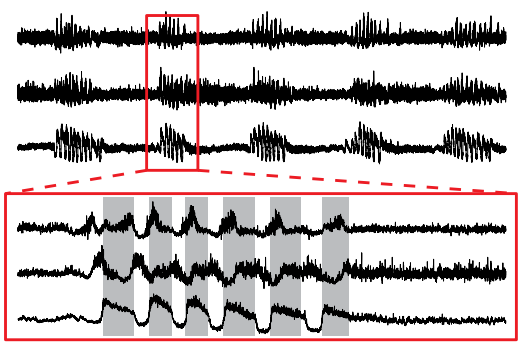

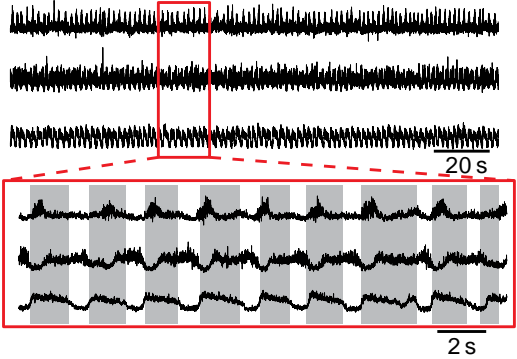

Eii iL2-L5 Fast Rhythm

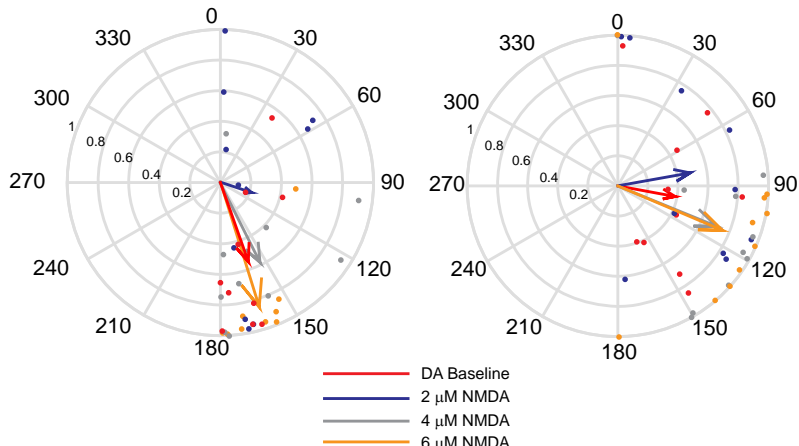

Figure 6. Sequential enhancement of network excitation with NMDA modulates dopamine-evoked rhythmicity. $\boldsymbol{A}$, Neurograms recorded from left and right L2 and right L5 ventral roots illustrate the experimental paradigm and resultant effect on rhythmicity. Bath 


\section{continued}

application of $50 \mu \mathrm{M}$ dopamine (DA) evoked a multirhythmic pattern of motor activity that is modulated as network excitation is boosted by sequentially increasing the concentration of NMDA in the bath (red arrows). When NMDA is increased to $6 \mu \mathrm{M}$, the pattern switches from multirhythmic to a single, continuous locomotor-like rhythm. $\boldsymbol{B}$, The frequency power distribution following dopamine application and subsequent excitability manipulation is illustrated in the cross-wavelet frequency power spectrogram over time with frequency on the left $y$-axis, time on the $x$-axis, and increasing power represented as warmer colors. $\boldsymbol{C}$, At $6 \mu \mathrm{M}$ NMDA, the pattern switches from multiple rhythms to a single continuous rhythm. $\boldsymbol{D}$, Regions of interest were selected around the fast and slow rhythms, and respective frequency and power for left and right L2 and L5 neurograms were analyzed over time. Increasing network excitation increased the power of the fast rhythm and decreased the power of the slow rhythm. Ei, Eii, The phase and regularity of the fast rhythm is presented in the circular plots in $\mathbf{E i}$ and $\mathbf{E i i}$, and illustrate the switch to a locomotor-like pattern at $6 \mu \mathrm{M}$ NMDA as the vector length increases and phase moves closer to $180^{\circ}$ in both the left and right L2s and ipsilateral L2-L5. The phase in circular plots is reported in degrees, with $180^{\circ}$ indicating an alternating pattern and $0^{\circ}$ being synchronous. The length of the arrows represents the mean vector length $(r)$ or robustness of the pattern. Each dot represents the average phase for an individual preparation for each respective experimental condition. Data are presented as the mean $\pm \mathrm{SD}$, with asterisks denoting a significant difference between the respective point and the rhythm at 20 min following dopamine application (\#p $<0.05$, \#\#p $<0.01$, \#\#\#p $<0.001$ ) using pairwise multiple-comparisons Tukey post hoc analysis when significant main effects on a repeated-measures ANOVA were found.

invertebrate systems (Gutierrez et al., 2013; Marder et al., 2014). Our work provides an understanding into the variability in modulatory action between preparations, which is a common challenge when studying network function in vitro. These results have important implications with respect to the effect of manipulations on cellular elements of the network that may move the network across state space.

Motor networks of the lumbar spinal cord are capable of generating a diverse array of rhythmic motor patterns, including locomotion, scratching, spontaneous activity, and other movements. Most studies exploring modulation of rhythms in vitro focus on a continuous locomotor-like rhythms (Kiehn and Kjaerulff, 1996; Kiehn et al., 1999; Madriaga et al., 2004; Pearlstein et al., 2005; Brownstone and Wilson, 2008; Hagglund et al., 2013), which coincide with state 4 in Figure 8. While different laboratories use varying concentrations of NMDA, 5- HT, or dopamine to elicit rhythmic activity (Cazalets et al., 1992; Whelan et al., 2000; Bonnot et al., 2002; Madriaga et al., 2004; Zhong et al., 2010, 2011; Sharples et al., 2015), what is of note is that once state 4 is reached it is characterized by stable alternating bursting. Indeed, although there are subtle differences in the rhythms published by various laboratories, what is perhaps most striking are the similarities in fictive locomotor patterns. One possibility could be that subtle modulatory effects may be less apparent during a high-conductance state (Berg et al., 2007). Previous work conducted by our laboratory used an unstable locomotor rhythm generated at the lower excitation region of state 4 to reveal the stabilizing effect of dopamine (Sharples et al., 2015). Others have shown a similar effect of oxytocin (Pearson et al., 2003; Dose et al., 2014). A revised interpretation of our previous findings in light of our recent data is illustrated in Figure 9. An important caveat is that our data examine a network in a state of development. We have interpreted this based on such a network and recognize that the adult network likely responds differently and that receptor densities and functional effects are known to change during development (Perrier and Hounsgaard, 2000; Clemens et al., 2012; Keeler et al., 2016; Picton and Sillar, 2016).

\section{Dopamine reveals state-dependent recruitment of spinally generated rhythmicity}

In the current work, the rhythmogenic effects of dopamine were dependent on the excitation state of the spinal cord. In particular, we demonstrate that manipulating network excitation can reproduce the same network output that we report only at high concentrations of dopamine. We replicated this finding using several complimentary nonspecific methods to manipulate network excitation, including increasing extracellular $\mathrm{KCl}$ and NMDA to increase excitation, and low $\mathrm{KCl}, \mathrm{Mg}^{2+}$, and APV to reduce network excitation. Our work does not suggest that neuromodulator action is wholly dependent on network excitability as modulators have network effects beyond solely increasing network excitation. For example, we found that $5-\mathrm{HT}$ can evoke rhythms that are qualitatively different from those of dopamine, but, notably, we found that the rhythms produced by $5-\mathrm{HT}$ are also dependent on excitation state. Indeed, simply altering the extracellular ionic composition of potassium and calcium is sufficient to drive rhythmicity at the network and interneuronal level through the recruitment of voltage-sensitive sodiumpersistent inward currents (Brocard et al., 2013).

In other states the situation is more complex. We found that the rhythm evoked by our initial concentration of dopamine that was used to modulate locomotion (Jiang et al., 1999; Whelan et al., 2000) does not resemble the rhythmic signature typically associated with walking. While the episodes of rhythmicity were regular, the phasing of the intraepisode fast rhythm between roots was less stable. Upon initial observation, one could conclude that this is the discrete rhythmic motor pattern evoked by dopamine. Others have explored rhythms that transit between states 1 and 3 (Fig. 8) and inferred a discrete modulatory function (Cazalets et al., 1992; Schmidt et al., 1998; Pearson et al., 2003; Gozal et al., 2014). It could therefore be argued that this multirhythmic pattern of activity may be a more nonphysiological motor pattern occupying state 3 and expressed under the lower levels of excitation present in reduced preparations of the nervous system.

On the other hand, neonatal rodent pups move toward the dam to suckle and toward their littermates to keep 


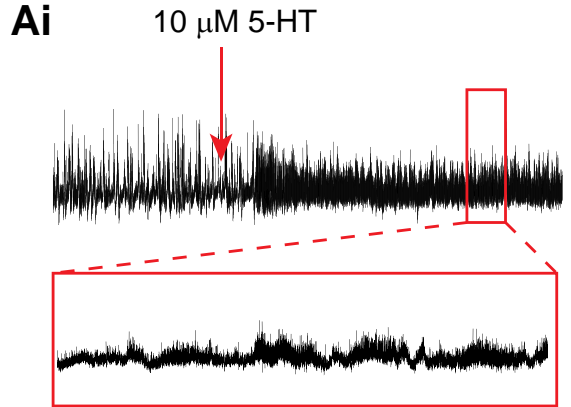

Bi

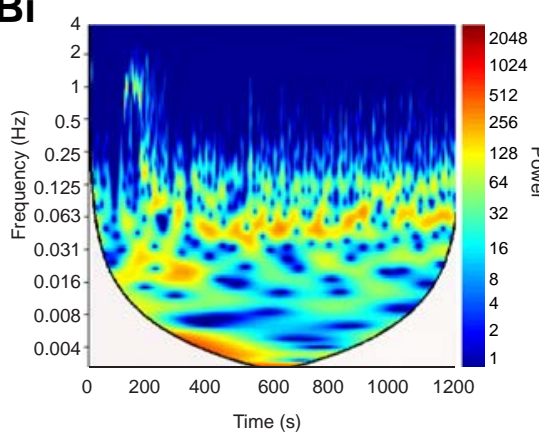

Aii $\quad 15 \mu \mathrm{M} 5-\mathrm{HT}$

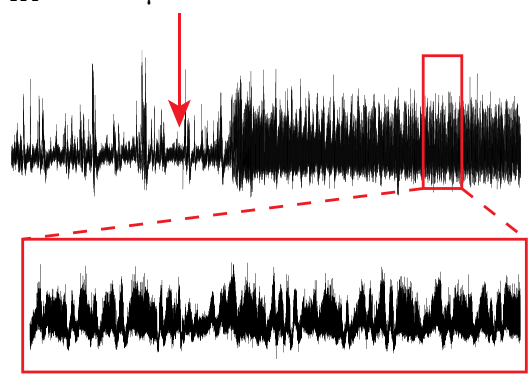

Bii

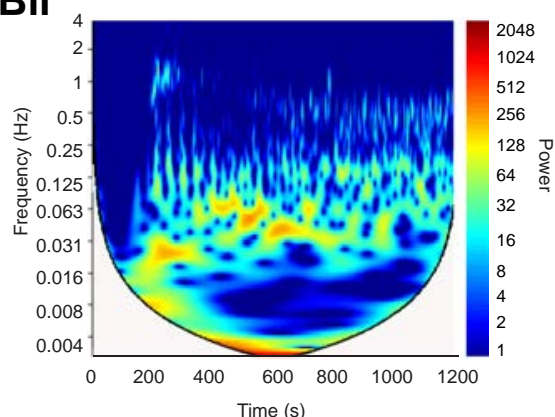

Aiii $\quad 20 \mu \mathrm{M} 5-\mathrm{HT}$

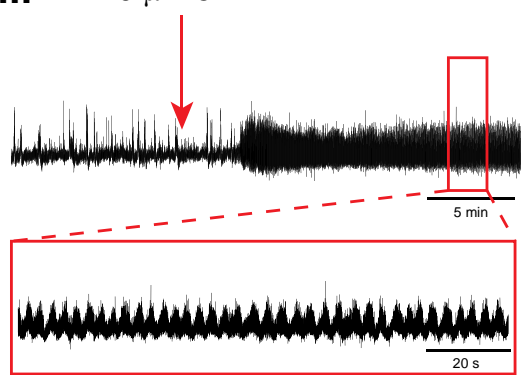

Biii

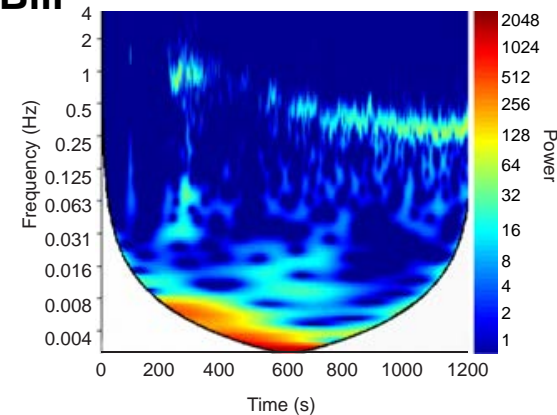

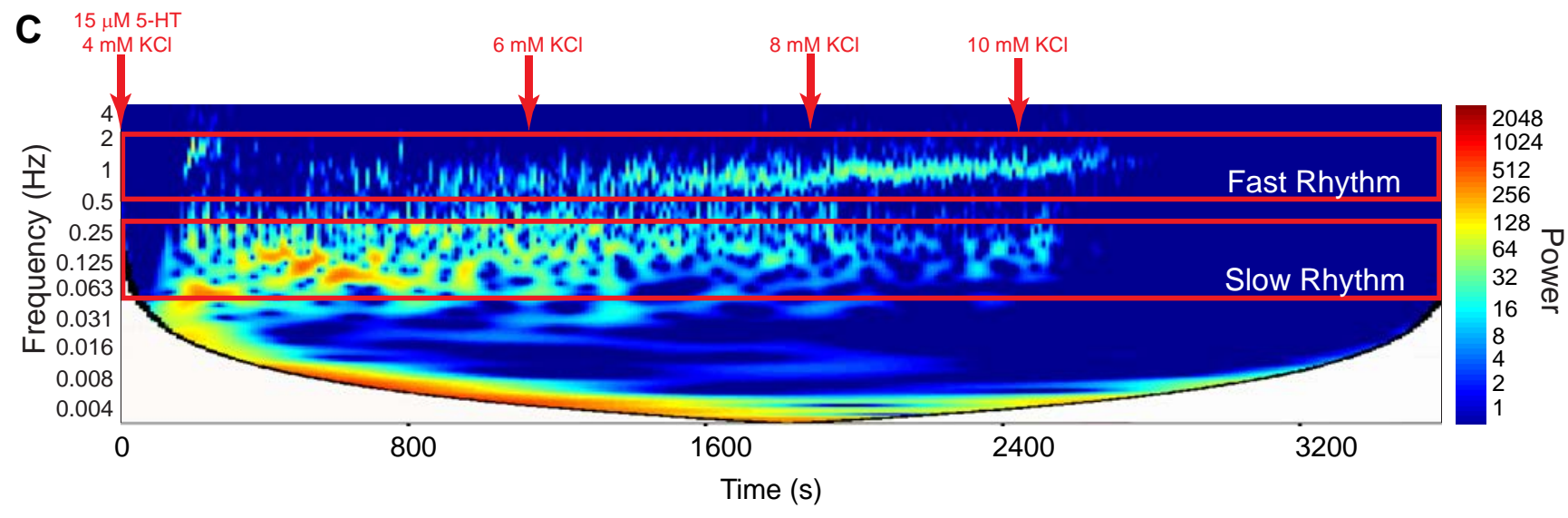

Di

Fast Rhythm

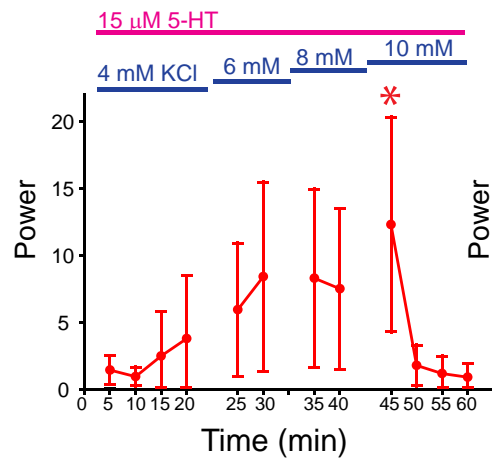

Dii

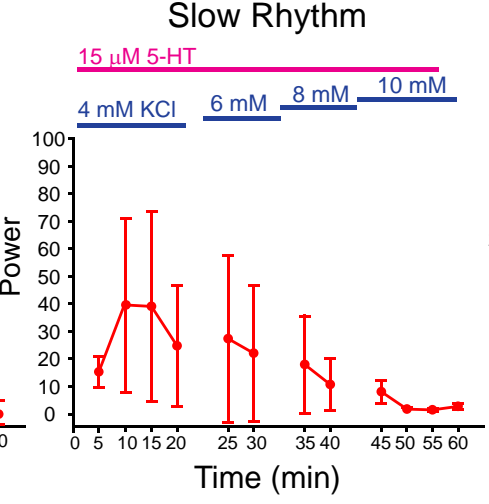

Ei L2-L2 Fast Rhythm Eii iL2-L5 Fast Rhythm
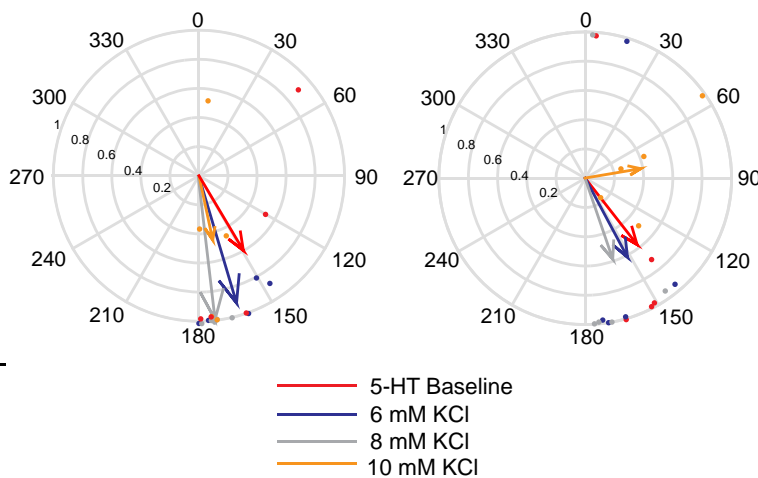

Figure 7. 5-HT evokes multirhythmic patterns of motor activity that become locomotor like as network excitation is enhanced with $\mathrm{KCl}$. Ai-Aiii, Neurograms recorded in separate experiments from single L2 ventral roots illustrate that bath application of $10 \mu \mathrm{M} 5$ - $\mathrm{HT}$ evokes a single slow rhythm (Ai), $15 \mu \mathrm{m}$ evokes a slow and fast rhythm (Aii), and $20 \mu \mathrm{m}$ evokes a single fast rhythm (Aiii). B, Autowavelet spectrograms depicted in $\boldsymbol{B} \boldsymbol{i}-\mathbf{B}$ iii illustrate these rhythms. $\boldsymbol{C}$, Boosting network excitation following the generation of multiple rhythms with $15 \mu \mathrm{m} 5-\mathrm{HT}$ caused a transition from a multirhythm to a single locomotor-like rhythm. Network manipulations are represented and highlighted as a red downward arrow in the spectrogram. $\boldsymbol{D}$, Regions of interest were selected within 


\section{continued}

cross-wavelet spectrograms around the fast and slow rhythms, and the respective frequency and power for left and right L2 and L5 were analyzed over time. Di, Div, Boosting network excitation increased the power of the fast rhythm (Di) and decreased the power of the slow rhythm (Div). Ei, Eii, The bursting pattern of the fast rhythm is presented in the circular plots in Ei and Eii, and illustrates an increase in the vector length at $10 \mathrm{~mm} \mathrm{KCl}$ in the left and right $\mathrm{L} 2 \mathrm{~s}$ and ipsilateral L2-L5 at $8 \mathrm{~mm} \mathrm{KCl,} \mathrm{but} \mathrm{at} 10 \mathrm{~mm}$ the length declined as activity became tonic. The phases in circular plots are reported in degrees, with $180^{\circ}$ indicating an alternating pattern and $0^{\circ}$ indicating a synchronous pattern. The lengths of arrows represent the mean vector length $(r)$ and angle or robustness of the pattern. Each dot represents the average phase for an individual preparation for each respective experimental condition. Data are presented as the mean \pm $\mathrm{SD}$, with asterisks denoting a significant difference between the respective point and the rhythm at 20 min following dopamine application $(* p<0.05)$ from Tukey post hoc analysis when significant main effects on a repeated-measures ANOVA were found.

warm. While neonates do not fully bear their weight or produce functional walking movements, they do produce a diverse array of rhythmic movements of the limbs that allow them to move around the nest. Although specula- tive, our work could be a representation of these diverse patterns that are expressed as networks enter transition zones during development. As descending pathways mature and the excitability of spinal networks becomes more

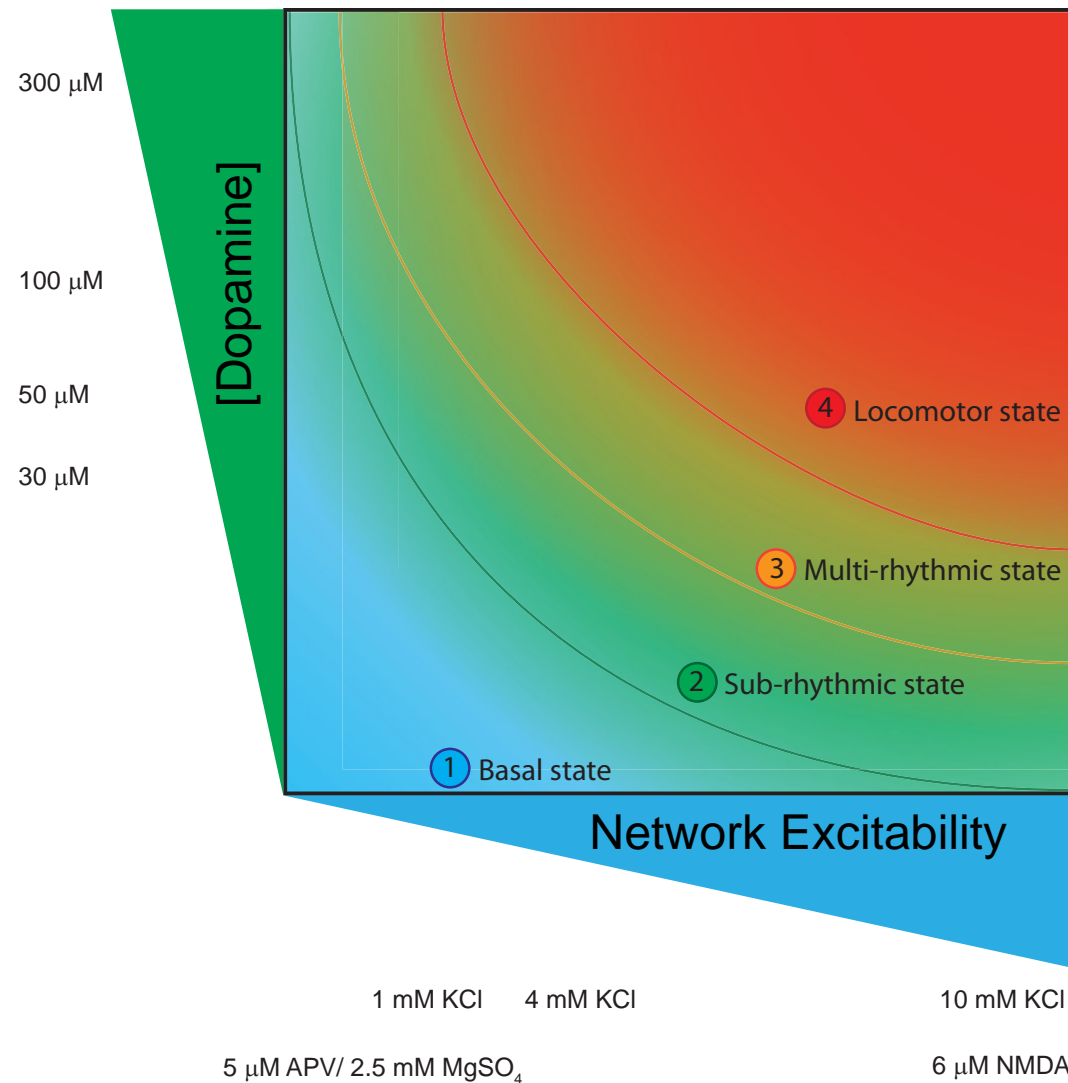

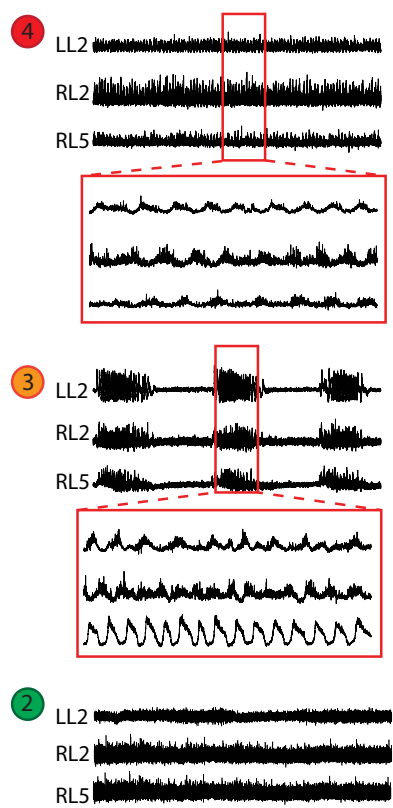

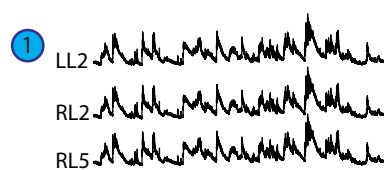

$5 \mu \mathrm{M}$ APV/ $2.5 \mathrm{mM} \mathrm{MgSO}$

$6 \mu \mathrm{M}$ NMDA

Basal state -Spontaneous activity characterized by stochastic episodes of tonic and rhythmic bursting

Sub-rhythmic state - tonic, no rhythmic activity

3 Multi-rhythmic state - multiple rhythms, diverse pattern

Locomotor state - single rhythm, locomotor pattern

Figure 8. Neuromodulators evoke rhythmicity by moving the network through an excitation parameter space with the end point pattern being locomotor like. State 1 (basal state) in isolated rodent spinal cords is characterized by spontaneous network activity. Depolarization of the network moves the network into a higher excitation state (state 2), which is characterized by tonic activity with no rhythmicity. State 3 is characterized by multirhythmic patterns of motor activity where modulator-specific patterns of rhythmic motor activity may exist. Finally, in state 4, the locomotor state is characterized by continuous rhythmic activity with an alternating locomotor-like pattern expressed as a network-emergent property at the highest level of network excitation. Neurograms depicted in the schematic are from ventral root recordings in the right L5 and left and right L2 spinal segments. Curved lines in the schematic represent transition zones between network states, where dopamine would be expected to have the greatest effects on network output. 
Ai

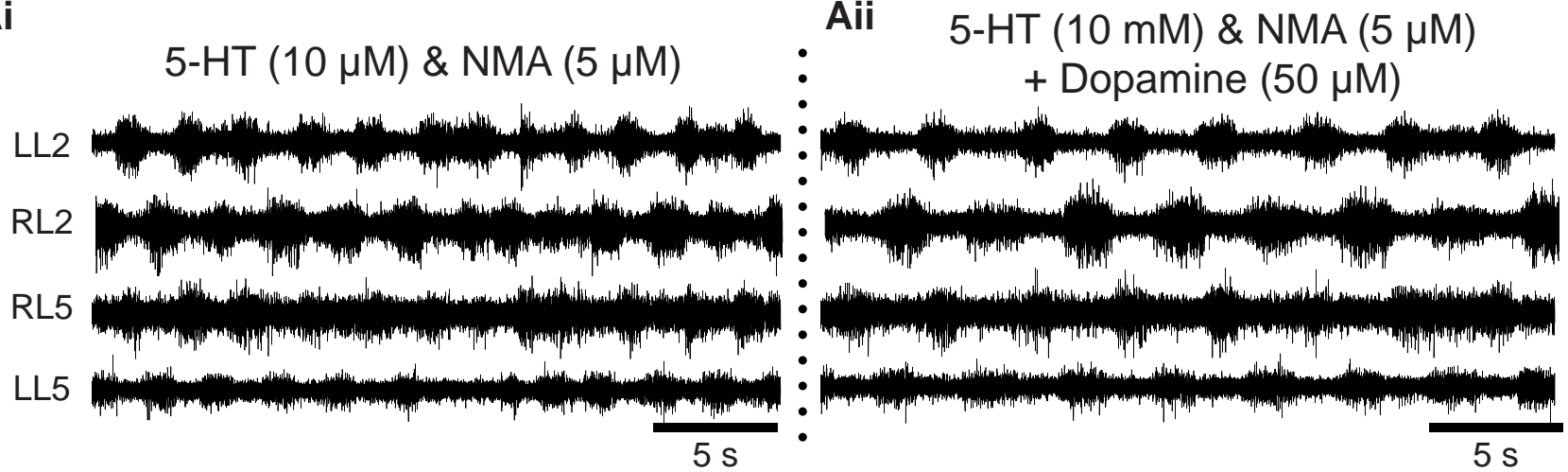

B

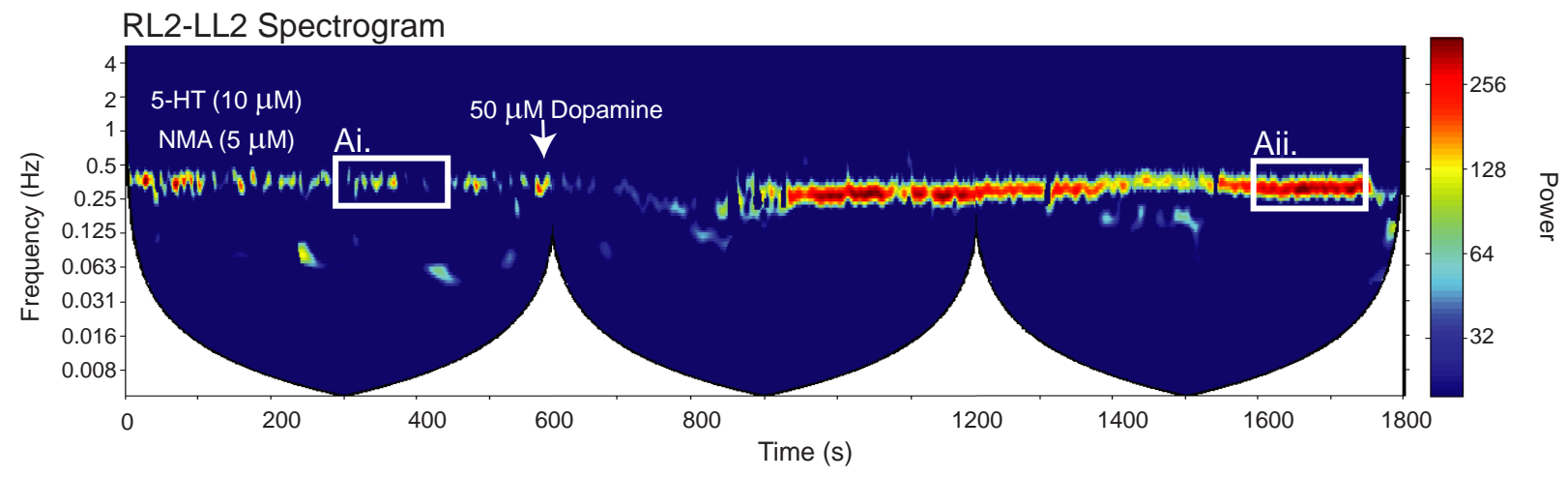

C

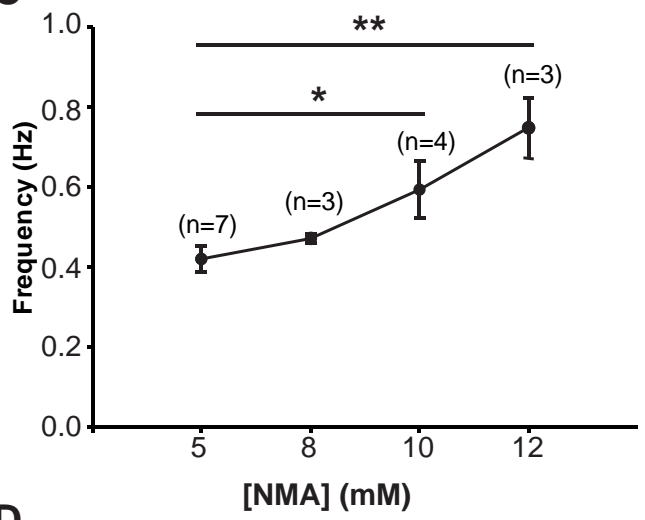

D

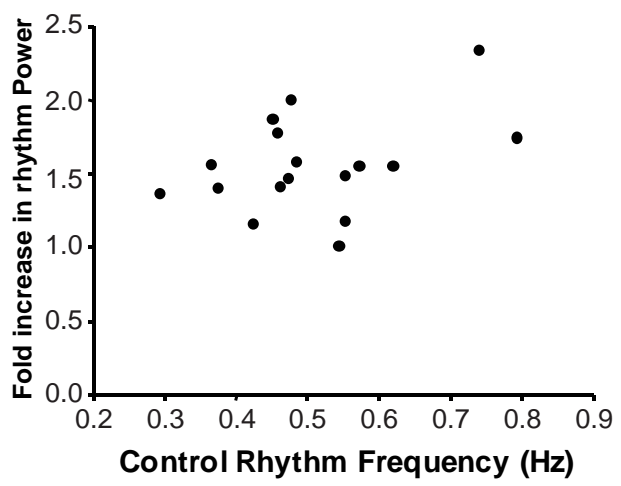

E

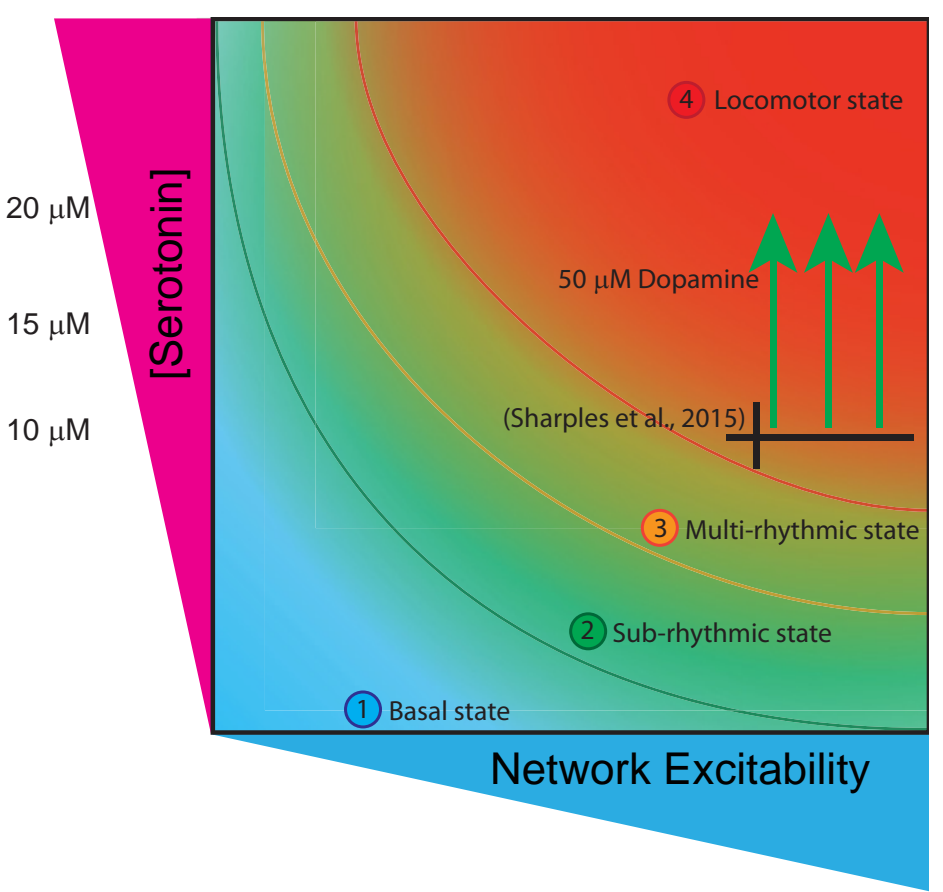

$5 \mu \mathrm{M}$ NMA $10 \mu \mathrm{M}$ NMA

Figure 9. Dopaminergic modulation of state 4. Dopamine exerts a robust modulation of locomotor-like activity at a position in the state space near a transition zone; however, overall the rhythm qualitatively stays the same, and the effect does not change when network excitation is manipulated. Ai, An unstable locomotor rhythm can be evoked by bath application of $10 \mu \mathrm{M} 5-\mathrm{HT}$ and $5 \mu \mathrm{M}$ NMDA. Aii, Dopamine reduces the frequency and stabilizes the locomotor rhythm. $\boldsymbol{B}$, This is particularly evident in the spectrogram. $\boldsymbol{C}$, $\boldsymbol{D}$, Network excitation was manipulated initially as a means of evoking rhythms of different frequencies but can also be interpreted as a network excitation state manipulation. $\boldsymbol{D}$, Regardless of the baseline frequency, the modulatory effect of dopamine on rhythm 
continued

robustness (power) was the same. $\boldsymbol{E}$, The respective position of the network within the locomotor state under each modulatory and excitability condition is plotted within the state space. These data have been previously published (Sharples et al., 2015), and we provide an updated interpretation of our findings in light of our current work.

robust, stable locomotor patterns similar to state 4 would begin to emerge. Similar to developing systems, pathological rhythmic motor patterns could also emerge in adults when spinal networks move into a lower excitation state due to impaired descending activation of spinal motor networks. In other systems, such as epilepsy, altered excitation states can produce slow rhythms similar to what we have observed, but any mechanistic similarities remain speculative at this point (Jensen and Yaari, 1997).

Finally, state 1 , or the basal state, in the neonatal rodent spinal cord is characterized by spontaneous activity. An interesting feature of spontaneous activity comes from previous work on the mouse where multiple rhythmic patterns were observed, from high-frequency synchronous bursts, to ipsilateral bursting and locomotor-like activity (Whelan et al., 2000). A hypothesis would then form that several transient states exist that converge onto a fourth locomotor-like state. We suspect that dopamine may be accessing a portion of these transient states and forming several identifiable and stable states. As to how dopamine can excite the cord forming regular episodes of rhythmic activity in state 3 , compared with stochastic activation with spontaneous bursting activity in state 1 is unclear.

\section{Implications and summary}

Our work illustrates at least four definable network states that restrict the effects that a neuromodulator can elicit within the lumbar spinal cord (Fig. 8). For example, the effects of dopamine on a stable locomotor-like pattern are arguably rather subtle-it does reduce the frequency and increase the amplitude of activity-but the rhythmic pattern remains qualitatively similar. This is very different if the network is transiting to state 4 , where dopamine has a large impact on network function, bursting becomes much more regular, and phasing between neurograms becomes locomotor like (Sharples et al., 2015). These effects are illustrated in Figure 9. We emphasize the importance of network excitation state when studying the contributions of identifiable cell types to the production of spinally generated rhythmic activity. The removal of elements that compose the central pattern generator may move the network into lower (or higher) regions of network state space. Caution is therefore advised on inferring neuronal sub-type function based on altered patterns of motor activity before moving the network through the full range of excitation state space. This leads us to propose that an important control would be to move the network excitability in the opposite direction to the hypothesized movement of the modulator. This would allow one to detail the contribution of circuit manipulation across defined network states.

\section{References}

Baghdadwala MI, Duchcherer M, Trask WM, Gray PA, Wilson RJ (2016) Diving into the mammalian swamp of respiratory rhythm generation with the bullfrog. Respir Physiol Neurobiol 224:37-51. CrossRef Medline

Bargmann Cl (2012) Beyond the connectome: how neuromodulators shape neural circuits. Bioessays 34:458-465. CrossRef Medline

Barrière G, Mellen N, Cazalets JR (2004) Neuromodulation of the locomotor network by dopamine in the isolated spinal cord of newborn rat. Eur J Neurosci 19:1325-1335. CrossRef Medline

Barrière G, Bertrand S, Cazalets JR (2005) Peptidergic neuromodulation of the lumbar locomotor network in the neonatal rat spinal cord. Peptides 26:277-286. CrossRef Medline

Berg RW, Alaburda A, Hounsgaard J (2007) Balanced inhibition and excitation drive spike activity in spinal half-centers. Science 315: 390-393. CrossRef Medline

Blitz DM, Nusbaum MP (2012) Modulation of circuit feedback specifies motor circuit output. J Neurosci 32:9182-9193. CrossRef Medline

Bonnot A, Whelan PJ, Mentis GZ, O'Donovan MJ (2002) Locomotorlike activity generated by the neonatal mouse spinal cord. Brain Res Brain Res Rev 40:141-151. Medline

Bouvier J, Caggiano V, Leiras R, Caldeira V, Bellardita C, Balueva K, Fuchs A, Kiehn O (2015) Descending command neurons in the brainstem that halt locomotion. Cell 163:1191-1203. CrossRef Medline

Brocard F, Shevtsova NA, Bouhadfane M, Tazerart S, Heinemann U, Rybak IA, Vinay L (2013) Activity-dependent changes in extracellular $\mathrm{Ca} 2+$ and $\mathrm{K}+$ reveal pacemakers in the spinal locomotorrelated network. Neuron 77:1047-1054. CrossRef

Brownstone RM, Wilson JM (2008) Strategies for delineating spinal locomotor rhythm-generating networks and the possible role of Hb9 interneurones in rhythmogenesis. Brain Res Rev 57:64-76. CrossRef

Cazalets JR, Sqalli-Houssaini Y, Clarac F (1992) Activation of the central pattern generators for locomotion by serotonin and excitatory amino acids in neonatal rat. J Physiol 455:187-204. CrossRef

Christie KJ, Whelan PJ (2005) Monoaminergic establishment of rostrocaudal gradients of rhythmicity in the neonatal mouse spinal cord. J Neurophysiol 94:1554-1564. CrossRef Medline

Clemens S, Belin-Rauscent A, Simmers J, Combes D (2012) Opposing modulatory effects of D1- and D2-like receptor activation on a spinal central pattern generator. J Neurophysiol 107:2250-2259. CrossRef

Cowley KC, Schmidt BJ (1997) Regional distribution of the locomotor pattern-generating network in the neonatal rat spinal cord. J Neurophysiol 77:247-259. Medline

Dose F, Zanon P, Coslovich T, Taccola G (2014) Nanomolar oxytocin synergizes with weak electrical afferent stimulation to activate the locomotor CpG of the rat spinal cord in vitro. PLoS One 9:e92967 CrossRef Medline

Gordon IT, Whelan PJ (2006) Monoaminergic control of caudaequina-evoked locomotion in the neonatal mouse spinal cord. $J$ Neurophysiol 96:3122-3129. CrossRef Medline

Gozal EA, O'Neill BE, Sawchuk MA, Zhu H, Halder M, Chou CC, Hochman S (2014) Anatomical and functional evidence for trace amines as unique modulators of locomotor function in the mammalian spinal cord. Front Neural Circuits 8:134. CrossRef

Grillner S, Wallén P, Saitoh K, Kozlov A, Robertson B (2008) Neural bases of goal-directed locomotion in vertebrates-an overview. Brain Res Rev 57:2-12. CrossRef Medline

Gutierrez GJ, Marder E (2014) Modulation of a single neuron has state-dependent actions on circuit dynamics. Eneuro 1:1-12. CrossRef 
Gutierrez GJ, O'Leary T, Marder E (2013) Multiple mechanisms switch an electrically coupled, synaptically inhibited neuron between competing rhythmic oscillators. Neuron 77:845-858. CrossRef

Hagglund M, Dougherty Kj, Borgius L, Itohara S, Iwasato T, Kiehn O (2013) Optogenetic dissection reveals multiple rhythmogenic modules underlying locomotion. Proc Natl Acad Sci U S A 110:1158911594. CrossRef

Heckman CJ, Johnson MD (2014) Reconfiguration of the electrical properties of motoneurons to match the diverse demands of motor behavior. Adv Exp Med Biol 826:33-40. CrossRef Medline

Hentall ID, Mesigil R, Pinzon A, Noga BR (2003) Temporal and spatial profiles of pontine-evoked monoamine release in the rat's spinal cord. J Neurophysiol 89:2943-2951. CrossRef Medline

Hultborn H, Nielsen JB (2007) Spinal control of locomotion-from cat to man. Acta Physiol (Oxf) 189:111-121. CrossRef Medline

Humphreys JM, Whelan PJ (2012) Dopamine exerts activationdependent modulation of spinal locomotor circuits in the neonatal mouse. J Neurophysiol 108:3370-3381. CrossRef

Jensen MS, Yaari Y (1997) Role of intrinsic burst firing, potassium accumulation, and electrical coupling in the elevated potassium model of hippocampal epilepsy. J Neurophysiol 77:1224-1233.

Jiang Z, Carlin KP, Brownstone RM (1999) An in vitro functionally mature mouse spinal cord preparation for the study of spinal motor networks. Brain Res 816:493-499. CrossRef

Jordan LM, Liu J, Hedlund PB, Akay T, Pearson KG (2008) Descending command systems for the initiation of locomotion in mammals. Brain Res Rev 57:183-191. CrossRef Medline

Keeler BE, Lallemand P, Patel MM, de Castro Brás LE, Clemens S (2016) Opposing aging-related shift of excitatory dopamine D1 and inhibitory D3 receptor protein expression in striatum and spinal cord. J Neurophysiol 115:363-369. CrossRef

Kiehn O (2016) Decoding the organization of spinal circuits that control locomotion. Nat Rev Neurosci 17:224-238. CrossRef Medline

Kiehn O, Kjaerulff O (1996) Spatiotemporal characteristics of 5-HT and dopamine-induced rhythmic hindlimb activity in the in vitro neonatal rat. J Neurophysiol 75:1472-1482.

Kiehn O, Sillar KT, Kjaerulff O, Mcdearmid JR (1999) Effects of noradrenaline on locomotor rhythm-generating networks in the isolated neonatal rat spinal cord. J Neurophysiol 82:741-746. Medline

Kimura Y, Satou C, Fujioka S, Shoji W, Umeda K, Ishizuka T, Yawo $\mathrm{H}$, Higashijima S (2013) Hindbrain V2a neurons in the excitation of spinal locomotor circuits during zebrafish swimming. Curr Biol 23:843-849. CrossRef

Koblinger K, Füzesi T, Ejdrygiewicz J, Krajacic A, Bains JS, Whelan PJ (2014) Characterization of $A 11$ neurons projecting to the spinal cord of mice. PLoS One 9:e109636. CrossRef Medline

Maclean JN, Cowley KC, Schmidt BJ (1998) NMDA receptormediated oscillatory activity in the neonatal rat spinal cord is serotonin dependent. J Neurophysiol 79:2804-2808. Medline

Madriaga MA, Mcphee LC, Chersa T, Christie KJ, Whelan PJ (2004) Modulation of locomotor activity by multiple 5-HT and dopaminergic receptor subtypes in the neonatal mouse spinal cord. J Neurophysiol 92:1566-1576. CrossRef

Marder E, O'leary T, Shruti S (2014) Neuromodulation of circuits with variable parameters: single neurons and small circuits reveal principles of state-dependent and robust neuromodulation. Annu Rev Neurosci 37:329-346. CrossRef

Marder E, Goeritz ML, Otopalik AG (2015) Robust circuit rhythms in small circuits arise from variable circuit components and mechanisms. Curr Opin Neurobiol 31:156-163. CrossRef Medline

Miles GB, Sillar KT (2011) Neuromodulation of vertebrate locomotor control networks. Physiology (Bethesda) 26:393-411. CrossRef Medline

Mor Y, Lev-Tov A (2007) Analysis of rhythmic patterns produced by spinal neural networks. J Neurophysiol 98:2807-2817. CrossRef Medline
Pearlstein E, Ben Mabrouk F, Pflieger JF, Vinay L (2005) Serotonin refines the locomotor-related alternations in the in vitro neonatal rat spinal cord. Eur J Neurosci 21:1338-1346. CrossRef Medline Pearson SA, Mouihate A, Pittman QJ, Whelan PJ (2003) Peptidergic activation of locomotor pattern generators in the neonatal spinal cord. J Neurosci 23:10154-10163. Medline

Perrier JF, Hounsgaard J (2000) Development and regulation of response properties in spinal cord motoneurons. Brain Res Bull 53:529-535. Medline

Picton LD, Sillar KT (2016) Mechanisms underlying the endogenous dopaminergic inhibition of spinal locomotor circuit function in Xenopus tadpoles. Sci Rep 6:35749. CrossRef

Picton LD, Nascimento F, Broadhead MJ, Sillar KT, Miles GB (2016) Sodium pumps mediate activity-dependent changes in mammalian motor networks. J Neurosci. Advance online publication. Retrieved January 19, 2017. doi:10.1523/JNEUROSCI.200516.2016.

Prinz AA, Bucher D, Marder E (2004) Similar network activity from disparate circuit parameters. Nat Neurosci 7:1345-1352. CrossRef Medline

Puhl JG, Mesce KA (2008) Dopamine activates the motor pattern for crawling in the medicinal leech. J Neurosci 28:4192-4200. CrossRef Medline

Roberts A, Li WC, Soffe SR (2012) A functional scaffold of CNS neurons for the vertebrates: the developing Xenopus laevis spinal cord. Dev Neurobiol 72:575-584. CrossRef

Schmidt BJ, Hochman S, Maclean JN (1998) NMDA receptormediated oscillatory properties: potential role in rhythm generation in the mammalian spinal cord. Ann N Y Acad Sci 860:189-202. CrossRef

Sharples SA, Whelan PJ (2015) Dopamine exerts concentrationdependent bidirectional modulation and evokes state-dependent rhythmicity in motor networks of the neonatal mouse spinal cord. Soc Neurosci Abstr 41:422.07.

Sharples SA, Humphreys JM, Jensen AM, Dhoopar S, Delaloye N, Clemens S, Whelan PJ (2015) Dopaminergic modulation of locomotor network activity in the neonatal mouse spinal cord. J Neurophysiol 113:2500-2510. CrossRef Medline

Sillar KT, Combes D, Simmers J (2014) Neuromodulation in developing motor microcircuits. Curr Opin Neurobiol 29:73-81. CrossRef Medline

Smith JC, Ellenberger HH, Ballanyi K, Richter DW, Feldman JL (1991) Pre-Bötzinger complex: a brainstem region that may generate respiratory rhythm in mammals. Science 254:726-729. CrossRef

Soffe SR, Roberts A (1989) The influence of magnesium ions on the NMDA mediated responses of ventral rhythmic neurons in the spinal cord of Xenopus embryos. Eur J Neurosci 1:507-515. Medline

Stadele C, Heigele S, Stein W (2015) Neuromodulation to the rescue: compensation of temperature-induced breakdown of rhythmic motor patterns via extrinsic neuromodulatory input. PLoS Biol 13:e1002265

van den Pol AN (1999) Hypothalamic hypocretin (orexin): robust innervation of the spinal cord. J Neurosci 19:3171-3182. Medline \&

Whelan P, Bonnot A, O'donovan MJ (2000) Properties of rhythmic activity generated by the isolated spinal cord of the neonatal mouse. J Neurophysiol 84:2821-2833. Medline

Whelan PJ, Hiebert GW, Pearson KG (1995) Stimulation of the group I extensor afferents prolongs the stance phase in walking cats. Exp Brain Res 103:20-30. CrossRef

Zhong G, Droho S, Crone SA, Dietz S, Kwan AC, Webb WW, Sharma K, Harris-Warrick RM (2010) Electrophysiological characterization of V2a interneurons and their locomotor-related activity in the neonatal mouse spinal cord. J Neurosci 30:170-182. CrossRef

Zhong G, Sharma K, Harris-Warrick RM (2011) Frequencydependent recruitment of V2a interneurons during fictive locomotion in the mouse spinal cord. Nat Commun 2:274 CrossRef 